This item was submitted to Loughborough's Research Repository by the author.

Items in Figshare are protected by copyright, with all rights reserved, unless otherwise indicated.

\title{
Repair of damage in aircraft composite sound-absorbing panels
}

PLEASE CITE THE PUBLISHED VERSION

http://dx.doi.org/10.1016/j.compstruct.2014.10.001

\section{PUBLISHER}

(c) Elsevier Ltd

\section{VERSION}

AM (Accepted Manuscript)

\section{PUBLISHER STATEMENT}

This work is made available according to the conditions of the Creative Commons Attribution-NonCommercialNoDerivatives 4.0 International (CC BY-NC-ND 4.0) licence. Full details of this licence are available at: https://creativecommons.org/licenses/by-nc-nd/4.0/

\section{LICENCE}

CC BY-NC-ND 4.0

\section{REPOSITORY RECORD}

Anoshkin, Aleksandr N., Valeriy Y. Zuiko, Mikhail A. Tashkinov, and Vadim V. Silberschmidt. 2019. "Repair of Damage in Aircraft Composite Sound-absorbing Panels". figshare. https://hdl.handle.net/2134/16620. 


\title{
Repair of Damage in Aircraft Composite Sound-Absorbing Panels
}

\author{
A.N. Anoshkin ${ }^{1}$, V.Y. Zuiko ${ }^{1}$, M.A. Tashkinov ${ }^{2 *}$, V.V. Silberschmidt ${ }^{3}$ \\ ${ }^{1}$ The Center for Aviation Composite Technologies, Perm National Research Polytechnic \\ University, 29 Komsomolsky Ave., 614990 Perm, Russia \\ ${ }^{2}$ The Center of Experimental Mechanics, Perm National Research Polytechnic University, 29 \\ Komsomolsky Ave., 614990 Perm, Russia \\ ${ }^{3}$ Wolfson School of Mechanical and Manufacturing Engineering, Loughborough University, \\ Loughborough Leicestershire LE11 3TU, U.K.
}

Abstract

This work is focused on analysis of mechanical behaviour of aircraft engine's sound-absorbing panels (SAPs) exposed to in-service damage. Its aim is to suggest techniques of local repair of damaged SAPs and estimation of their post-repair residual strength. Fibreglass laminate panels with tubular core and perforated elements were studied for this purpose. A mechanical behaviour of structural elements of the panels was modelled with the finite-element (FE) analysis, with through rupture considered as an in-service defect. A technique of defect repair without dismantling parts from the structure is introduced using a novel vacuumless technology. This procedure was implemented on specially produced samples and simulated with FE. Residual strength of repaired samples was compared with that of standard and ruptured ones both in compression and tension experiments and FE analysis. Conclusions about applicability limits of the presented method are provided.

\section{Introduction}

Composite materials are being increasingly used in aerospace application due to unique combination of their mechanical properties. Modern polymer-textile composites combine high strength and stiffness, and relatively low density of carbon or glass fibres with ductility of a resin matrix. Special ways to lay up thin (1/8 of a millimetre) plies of composites allows production of complex, large-scale structures, e.g. airplane wings [1, 2]. As a result, most recently developed and future commercial aircrafts contain more than $50 \%$ of composites. Since composites are lighter than traditionally used alloys, while their mechanical properties are even better, using these materials for aircraft parts provides significant benefits for solution of weight-reduction problem, crucial for aerospace applications [3].

Moreover, composites have also found some special applications in aircraft industry. A promising area of the use of polymer composites is sound-absorbing contours for aircraft engines. A noise level of passenger aircrafts is an important technical parameter, which determines their competitiveness to a large extent. Achieving good vibration and noise isolation is an important task in the design of aircraft engines [4, 5]. Sound-absorbing contours allow creating a reliable system for suppression of noise of aircraft engines operating in different modes (take-off and landing). Composite sound-absorbing panels (SAPs) used in these contours are the main focus of this study. 
The composite SAPs contours consist of glass-fibre laminate skins and a core sandwiched between, which can have a tubular, cellular or honeycomb structure (Fig. 1). The core functions as a resonance cell; after entering the cell, sound waves lose their intensity due to superimposition of direct and reflected waves. In some cases such panels implement not only a sound-absorbing function, but serve also as a load-bearing structural part. Therefore, ensuring their performance and structural integrity under various loading conditions is an important task.

Exposed to in-service mechanical loads and environmental conditions, sound-absorbing panels demonstrate initiation and evolution of vartious damage and failure modes, such as surface scratches, cuts, damage of one or more surface plies, shallow and through ruptures of the contour. Additionally, initiation of fracture in polymer laminates can be caused by microstructural defects induced during their manufacture [6, 7]. Hence, there is an urgent challenge to develop procedures of restoration of damaged component's strength and load-bearing capacity since replacement of the whole part or returning it to the manufacturer for repair in most cases is not cost-effective [8]. This becomes a motivation for developing robust and reliable on-site repair techniques that could be applied directly to an installed part with damage.

The problem of performance estimation for structures with defects can be reduced to the following steps: (i) analysis of impact of a defect size on the structure's functioning; (ii) determination of acceptable defect size; (iii) selection of repair method; (iv) assessment of residual strength of the structure with a repaired defect.

This paper presents numerical and experimental studies of behaviour of sound-absorbing panels with a tubular core exposed to a severe case of in-service damage - through-contour rupture. It also suggests and discusses techniques of on-site repair of damaged SAPs and estimation of their post-repair residual strength.

\section{Structure and model of sound-absorbing panels}

The studied sound-absorbing panel consists of three-ply 90/0/90 and two-ply 90/0 laminate skins and tubes with 20/-20 laminate faces (Fig. 2). Some structural elements were perforated, as these feature can be employed to enhance sound reduction of SAPs. Two types of perforation were used, both with circular holes and row offset. The first type is dense perforation with a distance between holes is $8.8 \mathrm{~mm}$, diameter of holes is $2.0 \mathrm{~mm}$. Perforation of the second type is sparse, with the same diameter of holes and distance of $17.7 \mathrm{~mm}$ between them. A three-ply skin and adjacent tube faces have the former type of perforation, while inner faces of the tubes are perforated with the latter one.

Apparently, residual strength of damaged panels depends on extent and nature of damage. Damage caused by impacts (e.g. dropped tools, service collisions) can often be a critical threat to their structural integrity $[9,10]$. The most challenging case in terms of repair was investigated through rupture of the SAP, which is characterized by breakdown of all reinforcement laminates. The aim was to develop an effective method of restoration of panels' strength with possibility of its on-site application. Thus, it was important to define principal structural parts that are most prone to fracture. 
The behaviour of specific structural elements of SAPs as well as their strength under loading can be determined using the finite-elements (FE) analysis [11-13]. Hence, 3D models of both standard SAPs and ones with through ruptures were developed (see Fig. 3). Dimensions of the modelled samples were $150 \mathrm{~mm} \times 350 \mathrm{~mm}$. A hole was placed in the central part of the damaged specimen to imitate an impact-caused rupture, characterized by damage of all reinforcing layers. The length of the defect was equal to nearly half of the specimen's width (see Fig. 4).

Thanks to symmetry of the modelled specimens, simulations can be reduced by investigation of their halves only. Gripping fixtures, used for installing a sample in a testing machine, were also modelled in order to reproduce a character of load application in real experiments. These fixtures consisted of steel pads, a gasket, a seal and bolts, as illustrated in Fig. 3c. The fixture system with 10 bolts as well as a straight shape of the specimen (without fillets) provided a uniform stress field and non-critical stress levels in the damaged region.

Initial mechanical properties and strength characteristics of the materials used in numerical studies were obtained in in-house tests and are shown in Tables 1 and 2.

Table 1. Properties of materials used in numerical studies

\begin{tabular}{|c|c|c|c|c|c|c|c|c|c|}
\hline Material & $\begin{array}{c}\mathrm{E}_{X}, \\
\mathrm{GPa}\end{array}$ & $\begin{array}{c}\mathrm{Ey}, \\
\mathrm{GPa}\end{array}$ & $\begin{array}{c}\mathrm{Ez}, \\
\mathrm{GPa}\end{array}$ & $\boldsymbol{v}_{X Y}$ & $\boldsymbol{v}_{Y Z}$ & $\boldsymbol{v}_{X Z}$ & $\begin{array}{c}\text { Gxy, } \\
\text { GPa }\end{array}$ & $\begin{array}{c}\text { Gyz, } \\
\text { GPa }\end{array}$ & $\begin{array}{c}\text { Gxz, } \\
\text { GPa }\end{array}$ \\
\hline $\begin{array}{c}\text { Fibre-glass } \\
\text { prepreg }\end{array}$ & 24.6 & 18.6 & 6.0 & 0.15 & 0.18 & 0.42 & 4.0 & 3.0 & 3.0 \\
\hline Resin & 2.9 & - & - & 0.36 & - & - & - & - & - \\
\hline
\end{tabular}

Table 2. Strength characteristics of materials

\begin{tabular}{|l|c|c|c|c|}
\hline \multirow{2}{*}{ Material } & \multicolumn{2}{|c|}{$\sigma_{X}, \mathrm{MPa}$} & \multicolumn{2}{l|}{$\sigma_{Y}, \mathrm{MPa}$} \\
\cline { 2 - 5 } & tension & compression & tension & compression \\
\hline Fibre-glass prepreg & 600 & 450 & 300 & 295 \\
\hline Resin & \multicolumn{2}{|c|}{$30-45$} & \multicolumn{2}{|c|}{$30-45$} \\
\hline
\end{tabular}

As SAPs with tubular fibreglass core were composed of laminates with different types of perforation, thickness and orientation of plies, for numerical studies of their mechanical properties and performance under specified loading it was necessary to obtain effective properties of each laminate.

\section{Effective properties of perforated and non-perforated laminates}


For non-perforated laminates effective properties were calculated using the theory of anisotropic plates, based on initial properties of materials (Table 1) $[14,15]$. Thus, the first step was determination of the stiffness matrix $C$ for each monolayer:

$$
[C]=\left[\begin{array}{ccc}
\frac{E_{1}}{1-v_{12} v_{21}} & \frac{v_{21} E_{1}}{1-v_{12} v_{21}} & 0 \\
\frac{v_{21} E_{1}}{1-v_{12} v_{21}} & \frac{E_{2}}{1-v_{12} v_{21}} & 0 \\
0 & 0 & G_{12}
\end{array}\right],
$$

where $E_{1}$ and $E_{2}$ are the materials' elasticity moduli along and across the fibres, respectively, $v_{12}$ and $v_{21}=v_{12} \frac{E_{2}}{E_{1}}$ are the Poisson's coefficients, $G_{12}$ is the shear modulus.

Then, stiffness matrices of each material were transformed into an arbitrary coordinate system depending on the fibres' angle $\gamma$ in each ply of the laminate:

$$
\left[C^{\prime}\right]=[T][C][T]^{-1},
$$

where $[T]$ is the translation matrix:

$$
[T]=\left[\begin{array}{ccc}
\cos (\gamma)^{2} & \sin (\gamma)^{2} & -2 \cos (\gamma) \sin (\gamma) \\
\sin (\gamma)^{2} & \cos (\gamma)^{2} & 2 \cos (\gamma) \sin (\gamma) \\
\cos (\gamma) \sin (\gamma) & -\cos (\gamma) \sin (\gamma) & \cos (\gamma)^{2}-\sin (\gamma)^{2}
\end{array}\right] .
$$

A stacking order of the laminate was set by the fibre angles $\gamma_{i}$ and thickness of plies $h_{i}$. An equivalent stiffness matrix for the laminate was defined as a sum of products of the stiffness matrix and thickness of each ply:

$$
[A]=\left[\sum_{i=1}^{n}\left[C^{\prime}\right]^{(i)} h_{i}\right],
$$

where $n$ is the number of plies in the laminate.

The effective properties of the laminate were obtained as follows:

$$
\begin{gathered}
E_{1}^{*}=\frac{\left(A_{11}-\frac{\left(A_{12}\right)^{2}}{A_{22}}\right)}{H}, E_{2}^{*}=\frac{\left(A_{22}-\frac{\left(A_{12}\right)^{2}}{A_{11}}\right)}{H}, \\
v_{12}^{*}=\frac{A_{12}}{A_{22}}, v_{21}^{*}=\frac{A_{12}}{A_{11}}, \\
G_{12}^{*}=\frac{A_{33}}{H},
\end{gathered}
$$


where $H=\sum_{i=1}^{n} h_{i}$ is the total thickness of the laminate.

The effective properties of the laminates without perforation were calculated using MathCAD software; the obtained results are presented in Table 3.

Table 3. Calculated effective properties of modelled laminâtess

\begin{tabular}{|c|c|c|c|c|c|c|c|c|c|c|}
\hline Laminate & Perforation & $\begin{array}{c}\mathbf{E}_{\mathbf{x}}, \\
\mathbf{G P a}\end{array}$ & $\begin{array}{c}\mathbf{E}_{\mathbf{y}}, \\
\mathbf{G P a}\end{array}$ & $\begin{array}{c}\mathbf{E}_{\mathbf{z},} \\
\mathbf{G P a}\end{array}$ & $\mathbf{v}_{\mathbf{x y}}$ & $\mathbf{v}_{\mathbf{y z}}$ & $\mathbf{v}_{\mathbf{x z}}$ & $\begin{array}{c}\mathbf{G}_{\mathbf{x y}}, \\
\mathbf{G P a}\end{array}$ & $\begin{array}{c}\mathbf{G}_{\mathbf{y z}}, \\
\mathbf{G P a}\end{array}$ & $\begin{array}{c}\mathbf{G}_{\mathbf{x z}}, \\
\mathbf{G P a}\end{array}$ \\
\hline $\begin{array}{c}\mathbf{2} \text { plies } \\
\mathbf{7 0 / - 7 0}\end{array}$ & No & 20.5 & 16.1 & 6.0 & 0.23 & 0.18 & 0.42 & 6.3 & 3.0 & 3.0 \\
\hline $\begin{array}{c}\mathbf{2} \text { plies } \\
\mathbf{9 0 / 0}\end{array}$ & No & 21.6 & 21.6 & 6.0 & 0.13 & 0.18 & 0.42 & 4.0 & 3.0 & 3.0 \\
\hline $\begin{array}{c}\mathbf{3} \text { plies } \\
\mathbf{9 0 / 0 / 9 0}\end{array}$ & No & 20.6 & 22.6 & 6.0 & 0.12 & 0.18 & 0.42 & 4.0 & 3.0 & 3.0 \\
\hline
\end{tabular}

Obtaining effective properties of the perforated laminates can be singled out as a separate task since direct modelling of such structural elements is connected with computational difficulties due to a large number of small-sized curved areas (holes) that require a fine FE mesh. Hence, numerical homogenisation was implemented before the analysis of damage in the perforated SAPs. As perforation was periodic, a representative volume element (RVE) of the laminate could be considered for assessment of their effective properties. Their dimensions were chosen as 60 $\mathrm{mm} \times 60 \mathrm{~mm}$ to include a significant number of perforation holes. The latter were calculated using numerical studies with different type of load applied to RVE. The considered laminates were orthotropic, characterized by nine independent elastic constants: the Young's moduli $E_{x}, E_{y}, E_{z}$, Poisson's ratios $v_{x y}, v_{y z}, v_{x z}$, and shear moduli $G_{x y}, G_{y z}, G_{x z}$. Three types of numerical experiments were implemented for each RVE of the perforated laminates: tension along axes $\mathrm{X}$ and Y to determine the effective Young's moduli and Poisson's ratios, and pure shear in the XY plane to calculate the shear moduli. In each case the laminate RVE model was subjected to a kinematic loading condition of $1 \mathrm{~mm}$ displacement on the corresponding border. The problem was solved with ANSYS Mechanical software employing Shell281 finite elements. This element has 8 nodes with 6 degrees of freedom in each node.

The obtained results for calculated stress fields for the representative volumes of perforated laminates are presented in Figs. 6-8.

The homogenized constants of the perforated laminates - the elastic moduli and Poisson's coefficient - were obtained with the following formulas:

$$
\begin{gathered}
E_{X}^{*}=\frac{\left\langle\sigma_{X}\right\rangle}{\varepsilon_{X}}, E_{Y}^{*}=\frac{\left\langle\sigma_{Y}\right\rangle}{\varepsilon_{Y}}, E_{Z}^{*}=\frac{\left\langle\sigma_{Z}\right\rangle}{\varepsilon_{Z}}, \\
G_{X Y}^{*}=\frac{\left\langle\tau_{X Y}\right\rangle}{\gamma_{X Y}}, G_{Y Z}^{*}=\frac{\left\langle\tau_{Y Z}\right\rangle}{\gamma_{Y Z}}, G_{X Z}^{*}=\frac{\left\langle\tau_{X Z}\right\rangle}{\gamma_{X Z}},
\end{gathered}
$$




$$
v_{x y}=\left|\frac{\varepsilon_{Y}}{\varepsilon_{X}}\right|, v_{Y Z}=\left|\frac{\varepsilon_{Z}}{\varepsilon_{Y}}\right|, v_{X Z}=\left|\frac{\varepsilon_{Z}}{\varepsilon_{X}}\right|,
$$

where strains $\varepsilon_{X}, \varepsilon_{Y}, \varepsilon_{Z}$ and $\gamma_{i j}$ were predetermined in the numerical experiments. The mean stress values were calculated using the following relation:

$$
\langle\sigma\rangle=\frac{\sum_{i=1}^{n} \sigma_{i} V_{i}}{V_{M}},
$$

where $n$ is number of finite elements in the RVE, $\sigma_{i}$ is stress in the $i^{\text {th }}$ finite element, $V_{i}$ is its volume, $V_{M}$ is the representative volume. The effective characteristics of the perforated laminates obtained with the discussed numerical homogenisation are summarized in Table 3.

Table 4. Effective properties of perforated laminates

\begin{tabular}{|c|c|l|l|l|l|l|l|l|l|c|}
\hline Laminate & Perforation & $\begin{array}{l}\mathbf{E}_{\mathbf{x}}, \\
\mathbf{G P a}\end{array}$ & $\begin{array}{l}\mathbf{E}_{\mathbf{y}}, \\
\mathbf{G P a}\end{array}$ & $\begin{array}{l}\mathbf{E}_{\mathbf{z}}, \\
\mathbf{G P a}\end{array}$ & $\mathbf{v}_{\mathbf{x y}}$ & $\mathbf{v}_{\mathbf{y z}}$ & $\mathbf{v}_{\mathbf{x z}}$ & $\begin{array}{l}\mathbf{G}_{\mathbf{x y}}, \\
\mathbf{G P a}\end{array}$ & $\begin{array}{l}\mathbf{G}_{\mathbf{y z}}, \\
\mathbf{G P a}\end{array}$ & $\begin{array}{l}\mathbf{G}_{\mathbf{x z}} \\
\mathbf{G P a}\end{array}$ \\
\hline $\begin{array}{c}\text { 3 plies } \\
\mathbf{9 0 / 0} / \mathbf{9 0}\end{array}$ & $\begin{array}{c}\text { Type 1 } \\
\text { (dense) }\end{array}$ & 16.6 & 16.8 & 6.0 & 0.3 & 0.18 & 0.42 & 3.4 & 3.0 & 3.0 \\
\hline $\mathbf{2}$ plies & $\begin{array}{c}\text { Type 1 } \\
\text { (d0/-70 }\end{array}$ & 16.9 & 17.1 & 6.0 & 0.25 & 0.18 & 0.42 & 2.9 & 3.0 & 3.0 \\
\hline $\mathbf{2}$ plies & $\begin{array}{c}\text { Type 2 } \\
\text { 70/-70 }\end{array}$ & 17.4 & 17.3 & 6.0 & 0.22 & 0.18 & 0.42 & 4.5 & 3.0 & 3.0 \\
\hline
\end{tabular}

\section{Numerical modelling of mechanical behaviour of panels}

The main numerical studies included development of finite-elements models of the considered SAP specimens under tensile loading. FE analysis was implemented employing the obtained effective properties of laminates for each structural component of the panels. Meshing was automatically implemented in ANSYS Workbench using tetrahedral elements. The mesh density was considered optimal when the difference between the results of successive calculations with a refined mesh did not exceed 5 - 10\%.

A mathematical formulation corresponded to the elasticity theory of anisotropic solids:

$$
\sigma_{i j, j}=0, \quad \varepsilon_{i j}=\frac{1}{2}\left(u_{i, j}+u_{j, i}\right), \quad \sigma_{i j}=C_{i j k l} \varepsilon_{k l} .
$$

The boundary conditions used for tension loading were symmetric on a border $\Gamma_{1}$ (see Fig. 9):

$$
\left\{\begin{array}{l}
\left.U_{Y}\right|_{\Gamma_{1}}=0 \\
\left.\tau_{X Y}\right|_{\Gamma_{1}}=\left.\tau_{Y Z}\right|_{\Gamma_{1}}=0
\end{array}\right.
$$

Displacements along axes $\mathrm{X}$ and $\mathrm{Y}$ on a border $\Gamma_{2}$ were constrained: 


$$
\left\{\begin{array}{l}
\left.U_{Y}\right|_{\Gamma_{2}}=0 \\
\left.U_{X}\right|_{\Gamma_{2}}=0
\end{array}\right.
$$

Thereby gripping of the test equipment as well as presence of a polymeric filler inside were taken into account. Loads were applied along the tension axis to each of the metallic bolts (boundary $\Gamma_{2}$ ):

$\left.P_{Y}\right|_{\Gamma_{2}}=100 \mathrm{kN}$.

Results of the numerical studies of SAP specimens under the prescribed loading conditions are shown on Fig. 8 -11, demonstrating distributions of displacements and stress fields in all structural components of the standard and damaged SAP specimens.

The maximal values of stresses corresponding to the applied tension load were found for elements of both types of the studied specimens and are presented in Table 4. 
Table 4. Maximal values of stresses for two studied specimens

\begin{tabular}{|c|c|c|c|c|}
\hline \multirow[b]{2}{*}{ Structural element } & \multirow[b]{2}{*}{ Perforation } & \multirow[b]{2}{*}{ Laminate } & \multicolumn{2}{|c|}{$\begin{array}{c}\text { Maximal stress } \\
\sigma_{\max }, \mathrm{MPa} \\
\end{array}$} \\
\hline & & & Axis $\mathrm{X}$ & Axis $Y$ \\
\hline \multicolumn{5}{|c|}{ Standard SAP specimen } \\
\hline Tubes & - & 2 plies 70/-70 & 34.3 & 163.5 \\
\hline Skin & - & 2 plies 90/0 & 22.3 & 249.3 \\
\hline Tubes & $\begin{array}{l}\text { Type } 1 \\
\text { (dense) }\end{array}$ & 2 plies 70/-70 & 33.3 & 175 \\
\hline Tubes & $\begin{array}{l}\text { Type } 2 \\
\text { (sparse) }\end{array}$ & 2 plies 70/-70 & 47.9 & 189.2 \\
\hline Skin & $\begin{array}{l}\text { Type } 1 \\
\text { (dense) } \\
\end{array}$ & 3 plies 90/0/90 & 22.5 & 205.5 \\
\hline \multicolumn{5}{|c|}{ SAP specimen with defect } \\
\hline Tubes & - & 2 plies 70/-70 & 129.8 & 573 \\
\hline Skin & - & 2 plies $90 / 0$ & 93.8 & 794 \\
\hline Tubes & $\begin{array}{l}\text { Type } 1 \\
\text { (dense) }\end{array}$ & 2 plies 70/-70 & 70.6 & 625 \\
\hline Tubes & $\begin{array}{l}\text { Type } 2 \\
\text { (sparse) }\end{array}$ & 2 plies 70/-70 & 135 & 677 \\
\hline Skin & $\begin{array}{l}\text { Type } 1 \\
\text { (dense) }\end{array}$ & 3 plies 90/0/90 & 106.6 & 664 \\
\hline
\end{tabular}

The magnitudes of breaking loads for each specimen were obtained by comparison the maximal stress values and strength characteristics from Table 2. For the standard sample, the structural elements most vulnerable to fracture are skins (both with and without perforation). The breaking load for them is $104 \mathrm{kN}$. The next are tubes' faces with dense perforation that would fail at 114 $\mathrm{kN}$. Most durable are non-perforated parts of the tubes: they can withstand tension up to $185 \mathrm{kN}$.

The specimen with defect demonstrates the following behaviour: its perforated skin and tubes' faces with dense perforation as well as the non-perforated skin and tubes' faces with sparse perforation fracture almost simultaneously, when load reaches $32 \mathrm{kN}$ and $33 \mathrm{kN}$, respectively. The non-perforrated parts of tubes are still the most durable, though the breaking load for them is more than three times less than that for the standard sample.

These results of numerical simulations confirmed that the panel's skins were the weakest part. This structural element would need repairs first in case of in-service damage. 


\section{Repair of SAPs with defects}

Due to a local nature of the studied type of defect it is important to investigate what kind of repair technique can restore load-bearing ability of the panel with minimal costs, technological skills and efforts. There are two commonly used types of composite structures' patching: mechanically fastened or adhesively bonded $[11,16]$. For sandwich laminate structures bonded composite repairs are more suitable since they allow avoiding stress concentration induced by mechanical fasteners [8, 11, 17, 18].

The method employed in this work presumes confining the repair procedure to application of nonperforated fibreglass laminate patches on the fractured skins. A full recovery of the panels by adding a patch for the core is complicated due to the problem of joining patch tubes to the original ones. Introducing perforation on the skins is also infeasible during a short-time procedure as it requires special equipment. The suggested principle of repair stipulates removal of the damaged layers and their replacement with reconstructing ones in compliance with direction of the original ones as well as adding two additional layers on top of the repaired spot on both sides of the SAP. Schematically this procedure is presented on Fig. 12. Dimensions and orientation of the replacement layers correspond to those of the damaged ones.

The specialized portative equipment ACR3 Hot Bonder was used for the repair procedure. Its main technical features include the ability to repair structural parts without removing them from the structure, which can significantly reduce costs and shorten the repair cycle. It also allows controlling the repair process in real time. The bonder heats the repair zone with a flexible silicone heater with temperature control according to a predetermined program, with a possibility of stepwise temperature increases with a given speed and duration. Moulding of the replacement plies was implemented with a contact method with a pressure of $0.1 \mathrm{kgf} / \mathrm{cm}^{2}$ (9.8 kPa). Hardening was performed at $60^{\circ} \mathrm{C}$ for 10 hours. Fractured and repaired samples are shown in Fig. 13.

The 3D FE model of the repaired SAPs samples with inner and outer patches was also developed (see Fig. 14). The same type of numerical simulations - as for the standard and damaged panels were performed with tension loading using the same mathematical formulation (Eqs. (10)-(12)) and previously obtained effective properties of laminates. The calculated displacements and stress fields for each structural element of the repaired panel are shown in Figs. 15 while the obtained maximal stress values are presented in Table 5. 
Table 5. Maximal values of stresses for repaired sample

\begin{tabular}{|c|c|c|c|c|}
\hline \multirow[b]{2}{*}{ Structural element } & \multirow[b]{2}{*}{ Perforation } & \multirow[b]{2}{*}{ Laminate } & \multicolumn{2}{|c|}{$\begin{array}{c}\text { Maximal stress } \\
\sigma_{\max }, \mathrm{MPa}\end{array}$} \\
\hline & & & Axis $X$ & Axis $Y$ \\
\hline Tubes & - & 2 plies $70 /-70$ & 32.4 & 181.9 \\
\hline Skin & - & 2 plies 90/0 & 29.8 & 255.9 \\
\hline Tubes & $\begin{array}{l}\text { Type } 1 \\
\text { (dense) }\end{array}$ & 2 plies $70 /-70$ & 35.9 & 190.3 \\
\hline Tubes & $\begin{array}{l}\text { Type } 2 \\
\text { (sparse) }\end{array}$ & 2 plies $70 /-70$ & 53.1 & 310 \\
\hline Skin & $\begin{array}{l}\text { Type } 1 \\
\text { (dense) }\end{array}$ & 3 plies 90/0/90 & 54.8 & 195.1 \\
\hline $\begin{array}{c}\text { Inner patch } \\
\text { (narrow tubes side) }\end{array}$ & - & 2 plies $90 / 0$ & 8 & 365.5 \\
\hline $\begin{array}{c}\text { Inner patch } \\
\text { (wide tubes side) }\end{array}$ & - & 3 plies 90/0/90 & 5.1 & 322 \\
\hline $\begin{array}{c}\text { Outer patch } \\
\text { (narrow tubes side) }\end{array}$ & - & 2 plies 90/0 & 3.5 & 311 \\
\hline $\begin{array}{c}\text { Outer patch } \\
\text { (wide tubes side) }\end{array}$ & - & 2 plies $0 / 90$ & 10.9 & 271 \\
\hline
\end{tabular}

The following breaking loads for the elements of the repaired sample were calculated using the approach discussed above for the standard and damaged specimens: $65 \mathrm{kN}$ for the tubes' faces with sparse perforation (inside the sample), $86 \mathrm{kN}$ for the inner skin patch (from the narrow tubes side), $167 \mathrm{kN}$ for the non-perforated parts of the tubes.

Thus, the results of finite-element analysis demonstrated that a breaking load for the repaired SAP is twice higher than for SAP with through rupture. The difference between the levels of breaking load of structural elements of the repaired and standard SAPs is within 20-60\%, which shows that the repair can partly restore the panel's strength.

To validate the developed numerical model and to understand better the panels' behaviour, the experimental studies are essential.

\section{Experimental analysis of SAP samples}

The implemented experimental program included tension and compression tests of three types of SAP specimens: (i) standard; (ii) with defects and (iii) repaired. Three samples of each type were manufactured. Laminates of the tubular core and outer skins were made of fiberglass and resin employing a traditional moulding technique. The tests were performed on a universal electromechanical testing system Instron 5882. The applied displacement speed was $5 \mathrm{~mm} / \mathrm{min}$ for tension tests and $2 \mathrm{~mm} / \mathrm{min}$ for compression tests. The loading curves for the SAP samples in tensile and compression tests are shown, respectively, in Fig. 18. 
Upon reaching the limiting load, an instantaneous rupture of perforated load-bearing occurred followed by separation of their fragments without perforation and tubular core; this corresponds to the behaviour of the specimens in FE simulations. The scatter in the measured values of the breaking load for different specimens can be explained by the inherent heterogeneity of the studied materials.

In the tension tests, two repaired SAP samples failed outside the repair zone, the third one - on the edge of this zone. This behaviour suggests that the repaired defect was not a main stress concentrator.

In the compression tests, the loading curves of two samples without defects have several drops, which can be explained by the local debonding of adhesive interface between the skins and the core with subsequent local buckling of the skins. In these tests, all the specimens with repaired zone failed in the defect area, as the tubular core was not restored making it the weakest section. Descending parts of the loading curves are related to the process of structural damage, followed by buckling of the skins and tubular core over the entire length of the specimen panels.

The results of the experiments are summarized in Tables 5 and 6.

Table 6. Results of tension tests of SAP samples

\begin{tabular}{|c|l|c|c|}
\hline \multirow{2}{*}{ Panel } & \multicolumn{1}{|c|}{ Specimen } & $\begin{array}{c}\text { Breaking load } \\
\mathbf{P}_{\mathbf{M a x}}, \mathbf{k N}\end{array}$ & $\begin{array}{c}\text { Elongation at } \\
\text { rupture, mm }\end{array}$ \\
\hline \multirow{4}{*}{ Standard } & 1 & 100.7 & 9.4 \\
\cline { 2 - 4 } & 2 & 100.7 & 10.1 \\
\cline { 2 - 5 } & 3 & 96.5 & 9.2 \\
\hline \multirow{5}{*}{ With defect } & 1 & 39.5 & 8.3 \\
\cline { 2 - 5 } & 2 & 53.1 & 7.5 \\
\cline { 2 - 5 } & 3 & 62.2 & 10.3 \\
\hline \multirow{5}{*}{ Repaired } & & & 9.01 \\
& 1 & 96.7 & 7.76 \\
\cline { 2 - 5 } & 2 & 75.8 & 8.75 \\
\cline { 2 - 5 } & 3 & 88.2 & \\
\hline
\end{tabular}


Table 6. Results of compression tests of SAP samples

\begin{tabular}{|l|c|c|}
\hline & $\begin{array}{l}\text { Breaking load } \\
\mathbf{P}_{\mathbf{M a x}}, \mathbf{k N}\end{array}$ & $\begin{array}{l}\text { Shortening at } \\
\text { rupture, } \mathbf{~ m m}\end{array}$ \\
\hline $\begin{array}{l}\text { Compression of } \\
\text { standard sample } \\
\text { panels }\end{array}$ & & \\
\hline Sample 1 & 68.4 & 5.93 \\
\hline Sample 2 & 62.3 & 5.35 \\
\hline Sample 3 & 64.0 & 5.85 \\
\hline $\begin{array}{l}\text { Compression of } \\
\text { sample panels with } \\
\text { defect }\end{array}$ & & \\
\hline Sample 1 & & \\
\hline Sample 2 & 33.1 & 3.0 \\
\hline Sample 3 & 31.2 & 2.6 \\
\hline $\begin{array}{l}\text { Compression of } \\
\text { repaired sample } \\
\text { panels }\end{array}$ & 41.8 & 3.6 \\
\hline Sample 1 & & \\
\hline Sample 2 & 44.3 & 4.23 \\
\hline Sample 3 & 36.5 & 3.81 \\
\hline
\end{tabular}

Some additional experimental results for the considered types of the samples can be found in [19].

As dimensions of the produced specimens may differ due to their manufacture, the values of breaking load cannot be used directly for comparison of their. Thus, it is essential to introduce new normalized value that will take into account the dimensional variability and its association with the breaking-load magnitudes. The effective tensile strength value can be employed as such normalized strength parameter; it can be calculated based on the breaking load $P_{\max }$ (in $\mathrm{kN}$ ) and mean geometrical parameters of the samples:

$$
\left.\sigma_{b}=\frac{P_{\max }}{\overline{b h}} 10^{3} \text { (in } \mathrm{MPa}\right),
$$

where $\bar{b}$ is mean width of the specimen's working zone, $\bar{h}$ is mean thickness of the specimen (both - in mm). These parameters were measured for each manufactured sample. In our FE studies they were defined by geometry of the developed 3D models. Tables 7 and 8 provide a comparison between the values of effective strength measured in tests and calculated numerically with the FE models for standard and repaired SAPs. The numerically calculated breaking loads were defined by the weakest structural elements. 
Table 7. Parameters and effective strength values for standard specimens

\begin{tabular}{|c|c|c|c|c|c|c|}
\hline & Specimen & $\begin{array}{c}\text { Working } \\
\text { zone } \\
\text { width, mm }\end{array}$ & $\begin{array}{c}\text { Thickness, } \\
\text { mm }\end{array}$ & $\begin{array}{c}\text { Breaking } \\
\text { load, kN }\end{array}$ & $\begin{array}{c}\text { Effective } \\
\text { tensile } \\
\text { strength, } \\
\text { MPa }\end{array}$ & $\begin{array}{c}\text { Mean } \\
\text { effective } \\
\text { strength, } \\
\text { MPa }\end{array}$ \\
\cline { 2 - 7 } & 1 & 150.21 & 25.396 & 100.6 & 26.4 & \multirow{2}{*}{26.2} \\
\hline \multirow{2}{*}{$\begin{array}{c}\text { Experimental } \\
\text { studies }\end{array}$} & 2 & 150.23 & 25.317 & 100.7 & 26.5 & \multirow{2}{*}{26.8} \\
\cline { 2 - 6 } & 3 & 150.15 & 25.133 & 96.5 & 25.6 & \multirow{2}{*}{28.8} \\
\hline \multirow{2}{*}{$\begin{array}{c}\text { Numerical } \\
\text { studies }\end{array}$} & & 150 & 24 & 104 & 28.8 & \\
\hline
\end{tabular}

Table 8. Parameters and effective strength values for repaired specimens

\begin{tabular}{|c|c|c|c|c|c|c|}
\hline & Specimen & $\begin{array}{c}\text { Working } \\
\text { zone } \\
\text { width, mm }\end{array}$ & $\begin{array}{c}\text { Thickness, } \\
\text { mm }\end{array}$ & $\begin{array}{c}\text { Breaking } \\
\text { load, kN }\end{array}$ & $\begin{array}{c}\text { Effective } \\
\text { tensile } \\
\text { strength, } \\
\text { MPa }\end{array}$ & $\begin{array}{c}\text { Mean } \\
\text { effective } \\
\text { strength, } \\
\text { MPa }\end{array}$ \\
\cline { 2 - 6 } & 1 & 146.44 & 26.28 & 96.7 & 25.1 & \multirow{2}{*}{2} \\
\hline \multirow{2}{*}{$\begin{array}{c}\text { Experimental } \\
\text { studies }\end{array}$} & 2 & 143.98 & 26.35 & 72.8 & 19.2 & \multirow{2}{*}{2.3} \\
\cline { 2 - 6 } & 3 & 148.31 & 26.16 & 88.2 & 22.7 & \multirow{2}{*}{18.1} \\
\hline \multirow{2}{*}{$\begin{array}{c}\text { Numerical } \\
\text { studies }\end{array}$} & & 150 & 24 & 65 & 18.1 & \\
\hline
\end{tabular}

The difference of 2.6 MPa (less than 10\%) between the values of mean effective strength obtained in experiments and numerical simulations for standard samples may be considered satisfactory agreement since the same order deflections were observed among tests results of identically produced samples. However, when comparing the effective tensile strength of the patched samples, difference between values is $18.8 \%$. This is due to the fact that the contact zones of the patch in the model are considered ideal, what could not be accomplished for the full-scale real specimens. 


\section{Conclusions}

A possibility of in-situ local repair of defects arising in service of typical elements of composite structures for aircraft engines, such as sound-absorbing panels (SAPs), has been considered. New vacuumless method of local repair of defects with reconstruction of damaged layers using modern specialized equipment was suggested. In order to predict and compare behaviour of the SAPs, samples of standard, defected and repaired panels were modelled and investigated with finite elements analysis. Required effective properties of perforated and non-perforated laminated structural elements were obtained numerically.

Experimental studies on the statistical residual strength of the SAP samples in tension and compression were performed. They showed that after the local repair of a defect area, compressive strength of the structure decreased by about $15-20 \%$ for all three samples. However, the tensile tests didn't reveal a clear strength reduction in repaired SAP specimens. Thus, the repaired samples demonstrated significantly improved strength properties, though the undertaken repair procedure didn't allow to reach their initial strength. This fact confirms the possibility of exploitation of the repaired structures for some applications with dominant tension loading, but also demonstrates the necessity of further studies on improving the repair technology.

\section{Acknowledgements}

This work was supported by The Royal Society and The Russian Foundation for Basic Research (project 13-01-92608).

\section{References}

[1] Lukaszewicz DHJA C, Potter KD. The engineering aspects of automated pre- preg layup: history, present and future. Composites Part B Engineering 2012;43(3):997-1009.

[2] Barbero EJ. Introduction to composite materials design. Boca Raton: CRC Press; 2011.

[3] Mangalgiri PD. Composite materials for aerospace applications. Bulletin of Materials Science 1999;22(3):657-664.

[4] Mahashabde A, Wolfe P, Ashok A, Dorbian C, He Q, Fan A, et al. Assessing the environmental impacts of aircraft noise and emissions. Progress in Aerospace Sciences 2011;47:15-52.

[5] Lawrence P. Meeting the challenge of aviation emissions: an aircraft industry perspective. Technology Analysis and Strategic Management; 2009. 21 (1) p. 79-92.

[6] L. Tong, AP Mouritz and MK Bannister 3D Fibre Reinforced Polymer Composites, Elsevier, 2002.

[7] Cantwell WJ, Morton J. The significance of damage and defects and their detection in composite materials: a review. The Journal of Strain Analysis for Engineering Design 1992;27(1):29-42.

[8] Armstrong KB, W Cole W, Bevan G. Care and repair of advanced composites.

London: SAE International; 2005. 
[9] Shyr TW, Pan YH. Impact resistance and damage characteristics of composite laminates. Composite Structures 2003;62(2):193-203.

[10] Abrate S. Impact on laminated composite materials. Applied Mechanics Reviews 1991;44(4):155-190.

[11] K.B. Katnam, L.F.M. Da Silva, T.M. Young Bonded repair of composite aircraft structures: A review of scientific challenges and opportunities. Progress in Aerospace Sciences 2013;61:2642.

[12] He X. A review of finite element analysis of adhesively bonded joints. International Journal of Adhesion and Adhesives 2011;31:248-264.

[13] Kanouté P, Boso DP, Chaboche JL, Schrefler BA. Multiscale methods for composites: a review. Archives of Computational Methods in Engineering 2009;16(1):31-75.

[14] Tsai SW, Wu E M. A general theory of strength for anisotropic materials. J Compos Mater 1971;5(1):58-80.

[15] Zhang YX, Yang CH. Recent developments in finite element analysis for laminated composite plates. Compos Struct 2009;88(1):147-57.

[16] Soutis C, Hu FZ. Design and performance of bonded patch repairs of composite structures. In: Proceedings of the Institution of Mechanical Engineers, Part G: Journal of Aerospace Engineering; 1997. 211(4) p. 263-271.

[17] Camanho PP, Lambert M. A design methodology for mechanically fastened joints in laminated composite materials. Composites Science and Technology 2006;66(15):3004-3020.

[18] Wang CH, Gunnion AJ. Optimum shapes of scarf repairs. Composites Part A Applied Science and Manufacturing 2009;40(9):1407-1418.

[19] Anoshkin AN, Vildeman VE, Lobanov DS, Chikhachev AI Evaluation of repair efficiency in structures made of fibrous polymer composite materials. Mechanics of Composite Materials 2014;50(3):311-316. 


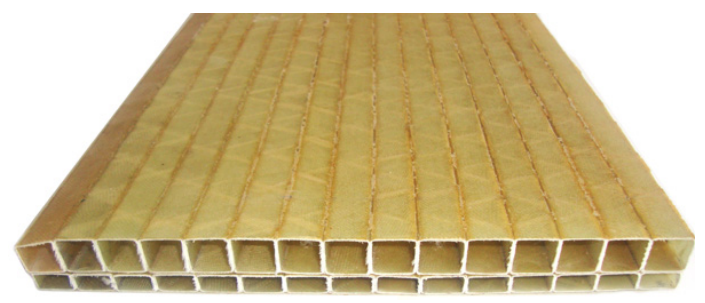

(a)

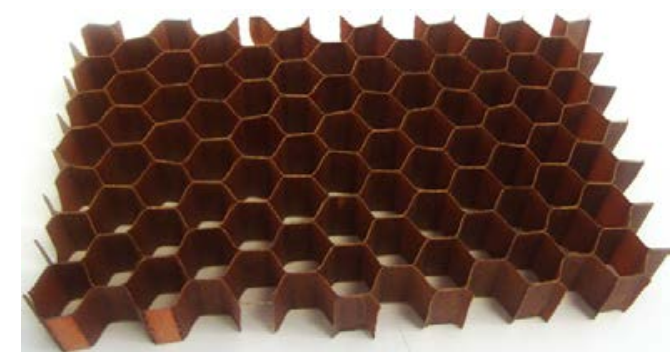

(b)

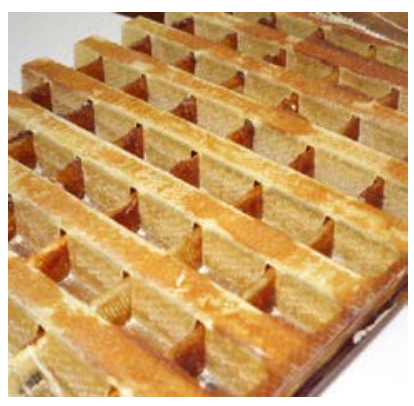

(c)

Figure 1. Core types of sound-absorbing panels: a) tubular; b) honeycomb; c) cellular

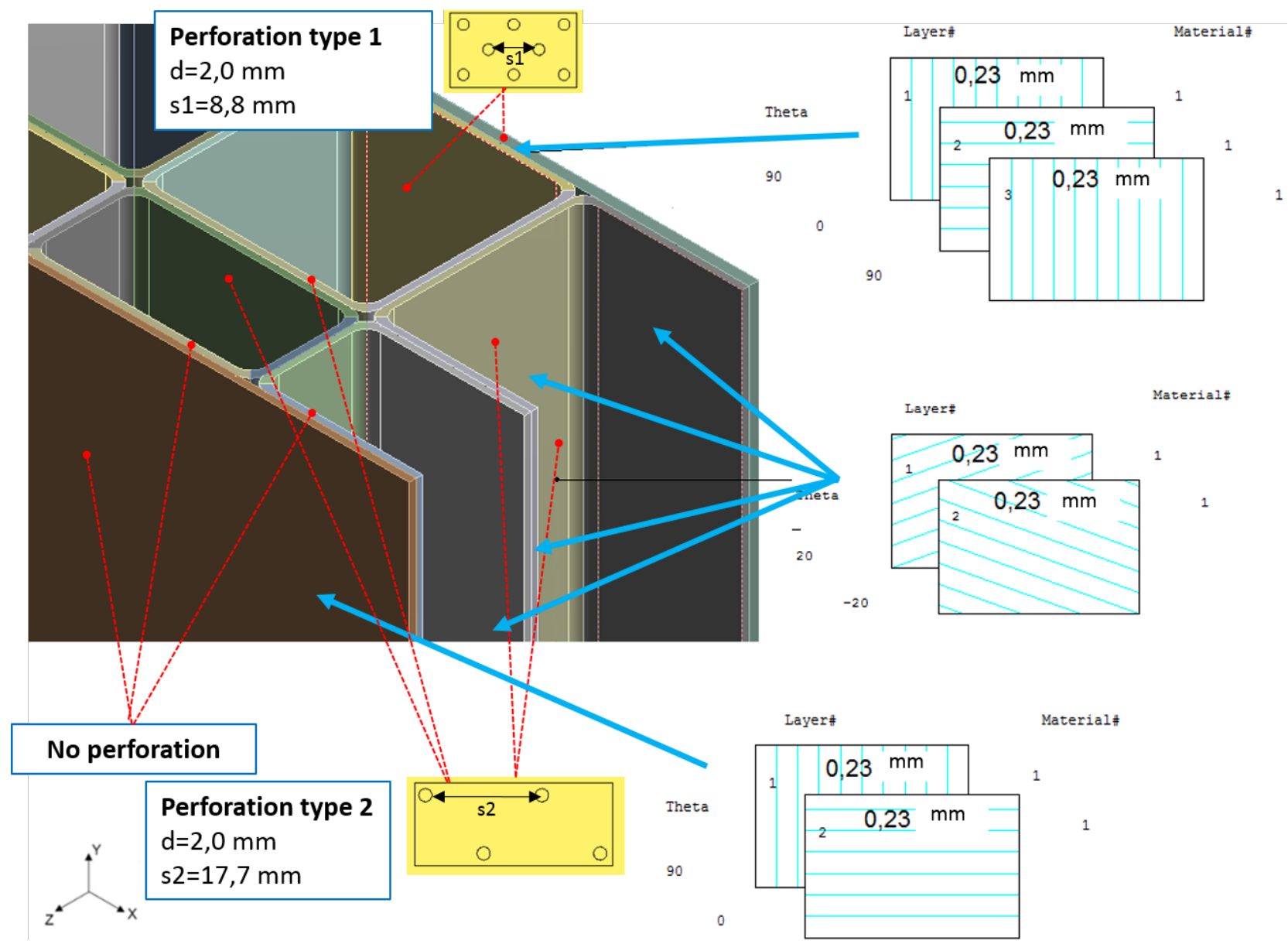

Figure 2. Layout of internal structure of sound-absorbing panel 


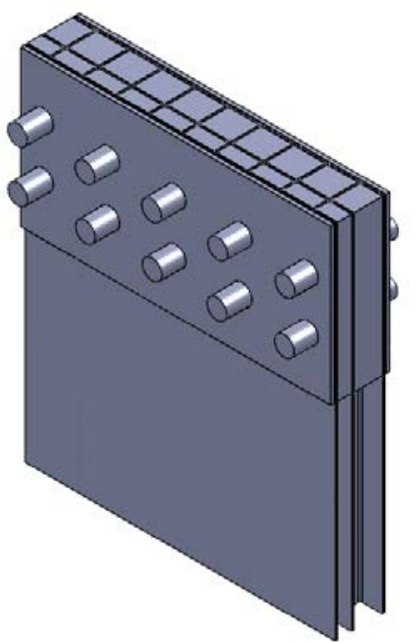

(a)

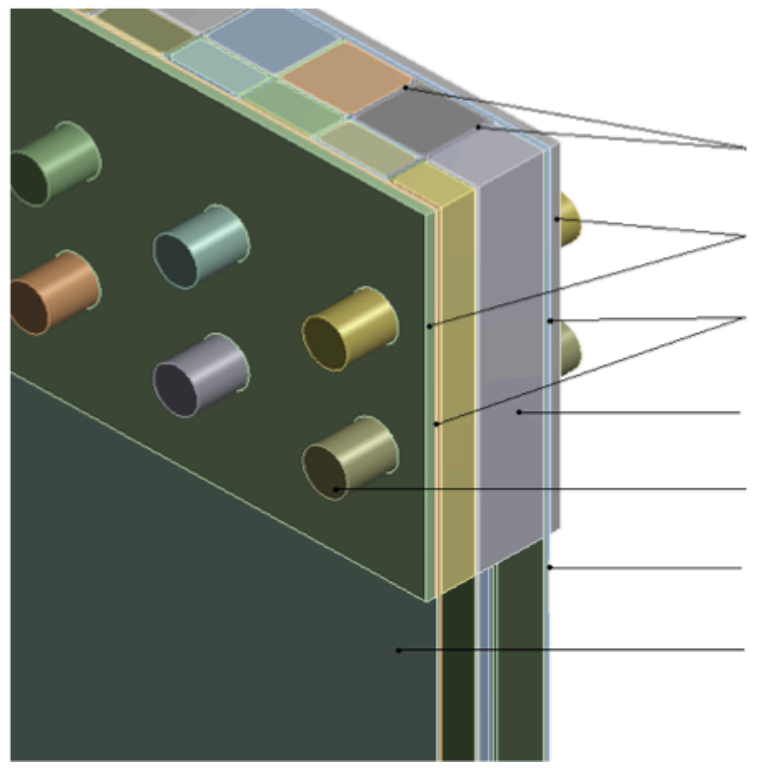

Tubes

Steel pads

Gasket

Seal

Bolts

Perforated

Non-perforated skin

Figure 3. 3D FE models of SAP: a) standard SAP; b) SAP with through rupture; (c) fixture for experimental testing

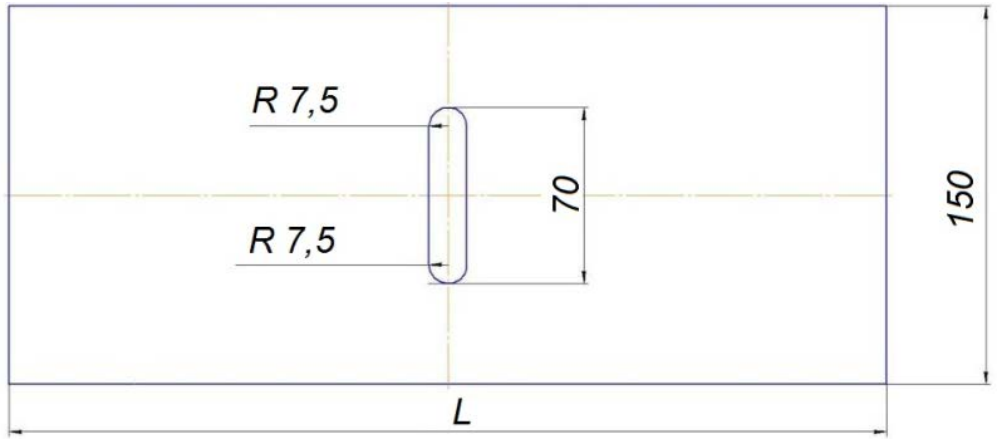

Figure 4. Dimensions of damaged SAP with central defect. For tension tests $L=350 \mathrm{~mm}$ 


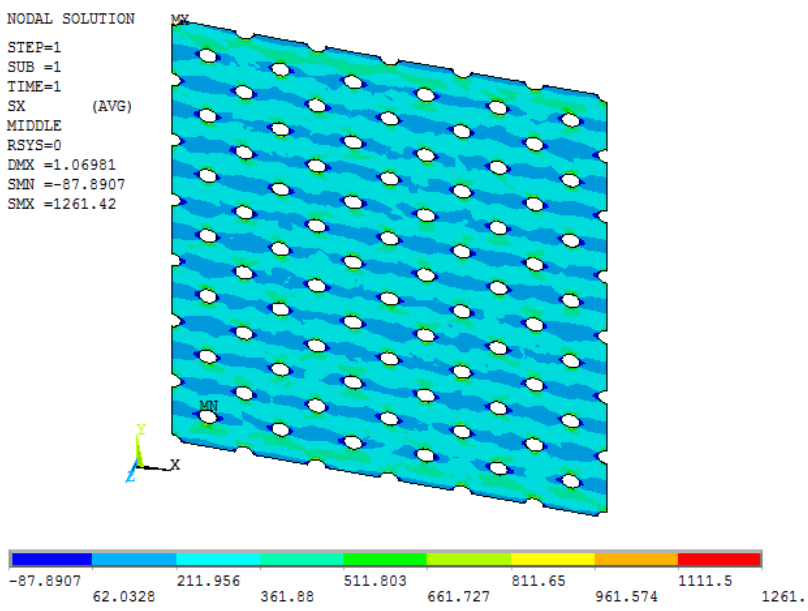

a)

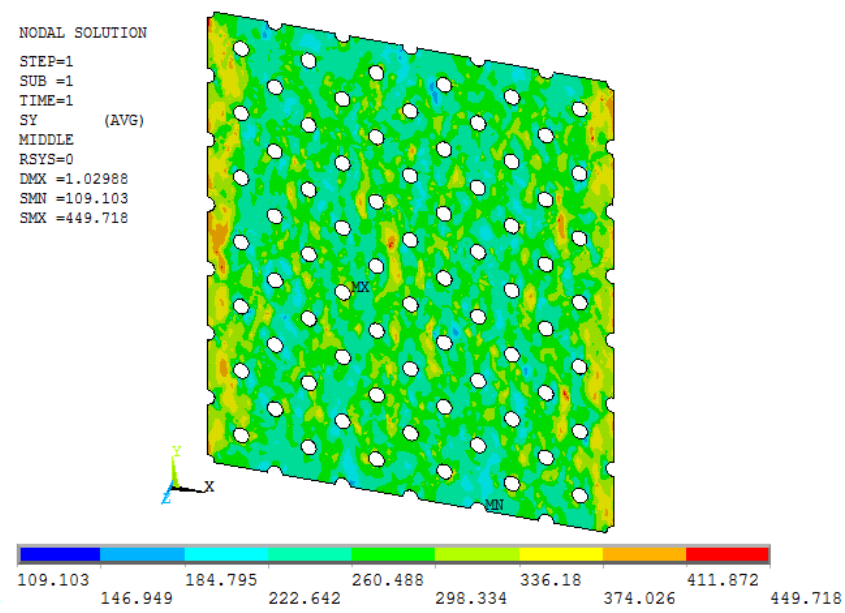

b)

$$
\begin{aligned}
& \text { NODAL SOLUTION } \\
& \text { SUB }=1 \\
& \text { TIME }=1 \quad \\
& \text { SXY } \\
& \text { MIDDLE } \quad \text { (AVG) } \\
& \text { RSYS }=0 \\
& \text { DMX }=.669852 \\
& \text { SMN }=-19.1155 \\
& \text { SMX }=632.379
\end{aligned}
$$
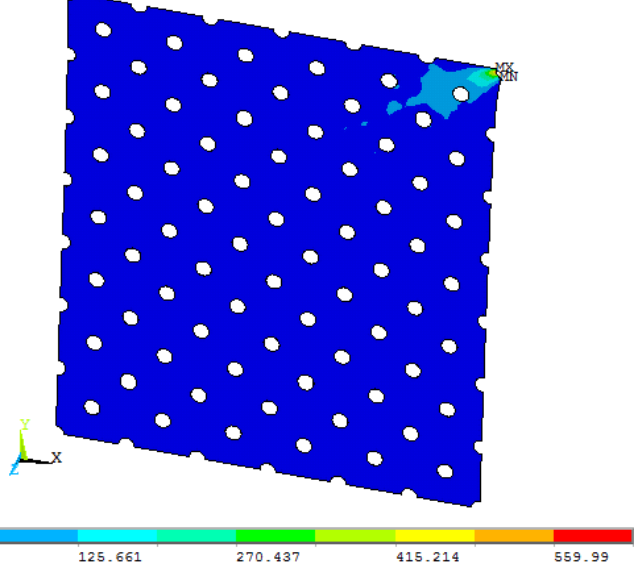

c)

Figure 5. Stress fields in RVE of perforated 90/0/90 laminate for skin (Type 1 dense perforation): $\mathrm{a}$ - tension along $\mathrm{X}$; $\mathrm{b}$ - tension along $\mathrm{Y}$; $\mathrm{c}-\mathrm{XY}$ shear 


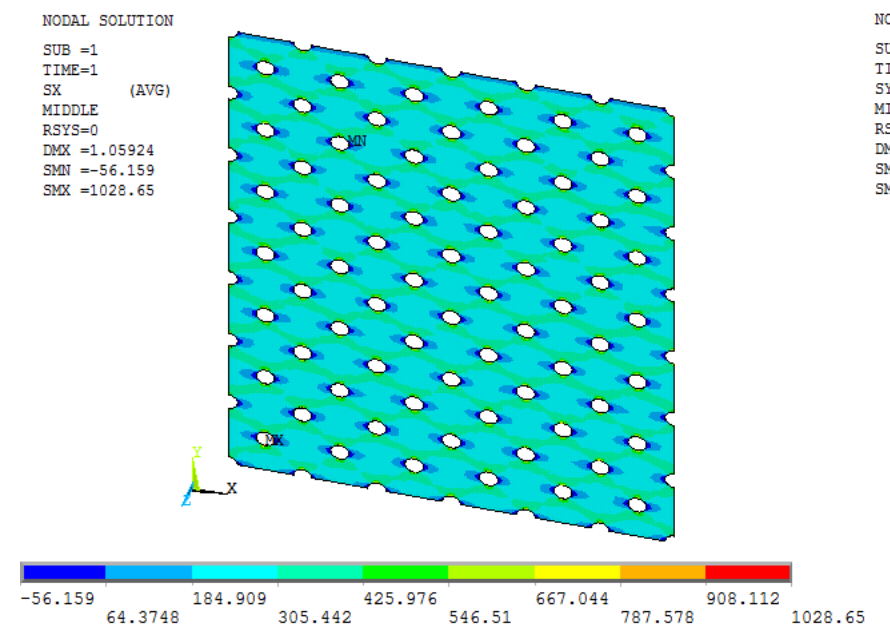

a)

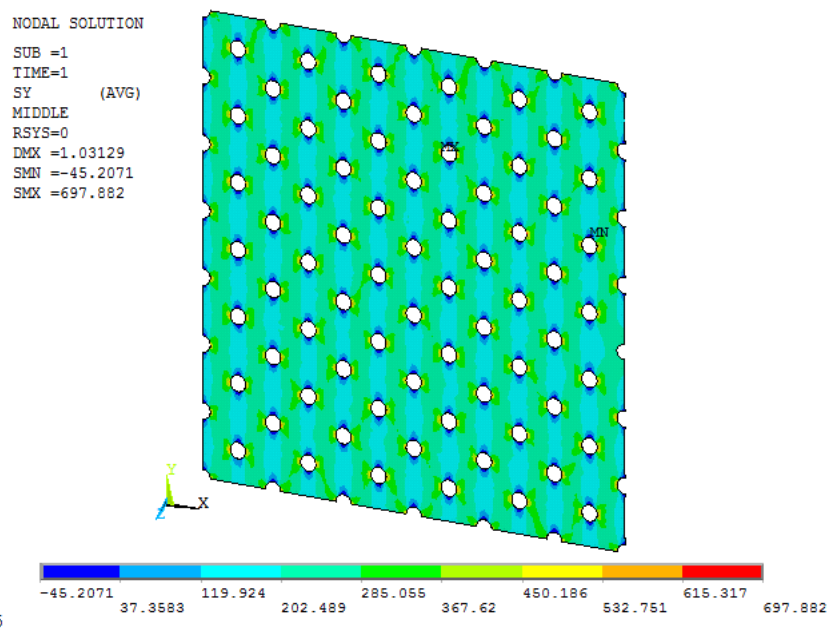

b)

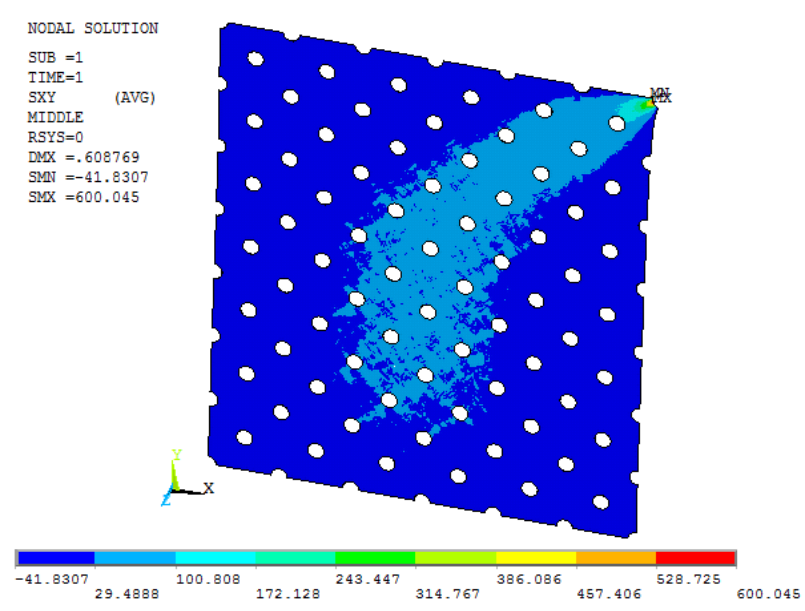

c)

Figure 6. Stress fields in RVE of perforated 70/-70 laminate for tubes (Type 1 dense perforation): $\mathrm{a}$ - tension along $\mathrm{X}, \mathrm{b}-$ tension along $\mathrm{Y}$; $\mathrm{c}-\mathrm{XY}$ shear 


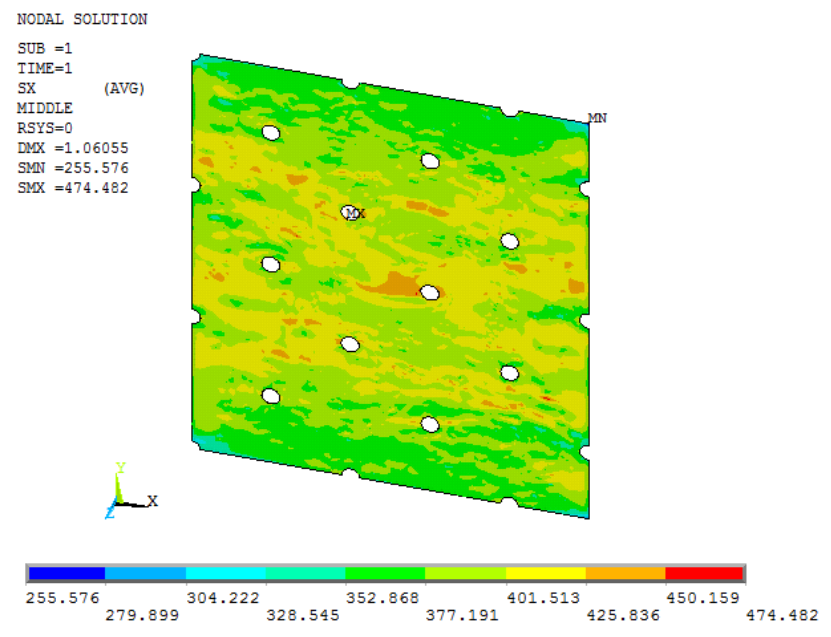

a)

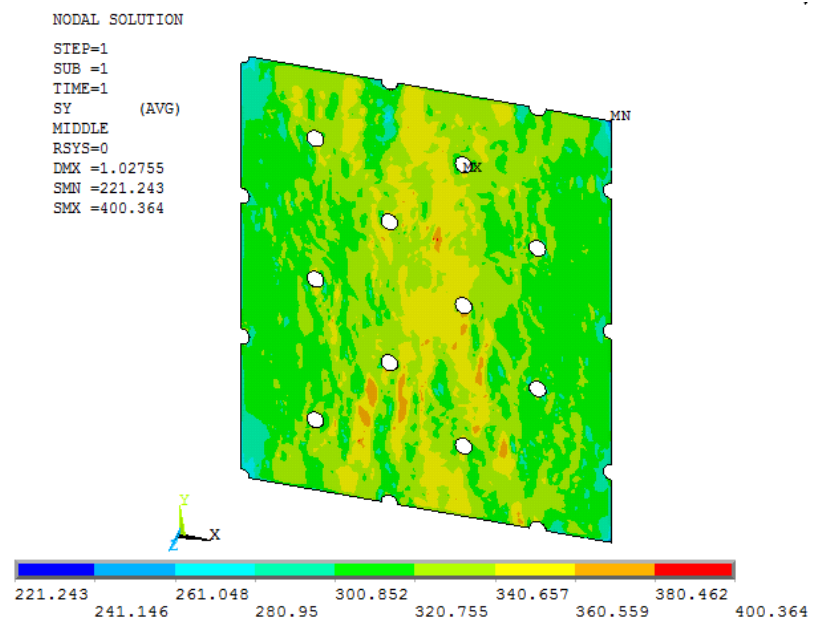

b)

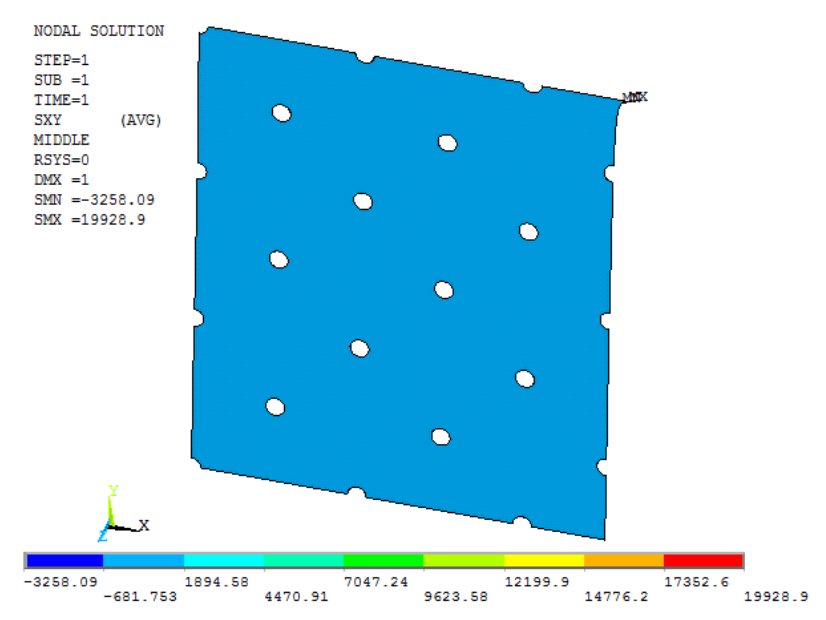

c)

Figure 7. Stress fields in RVE of perforated 70/-70 laminate for tubes (Type 2 sparse perforation): $\mathrm{a}$ - tension along $\mathrm{X} ; \mathrm{b}$ - tension along $\mathrm{Y}$; $\mathrm{c}-\mathrm{XY}$ shear
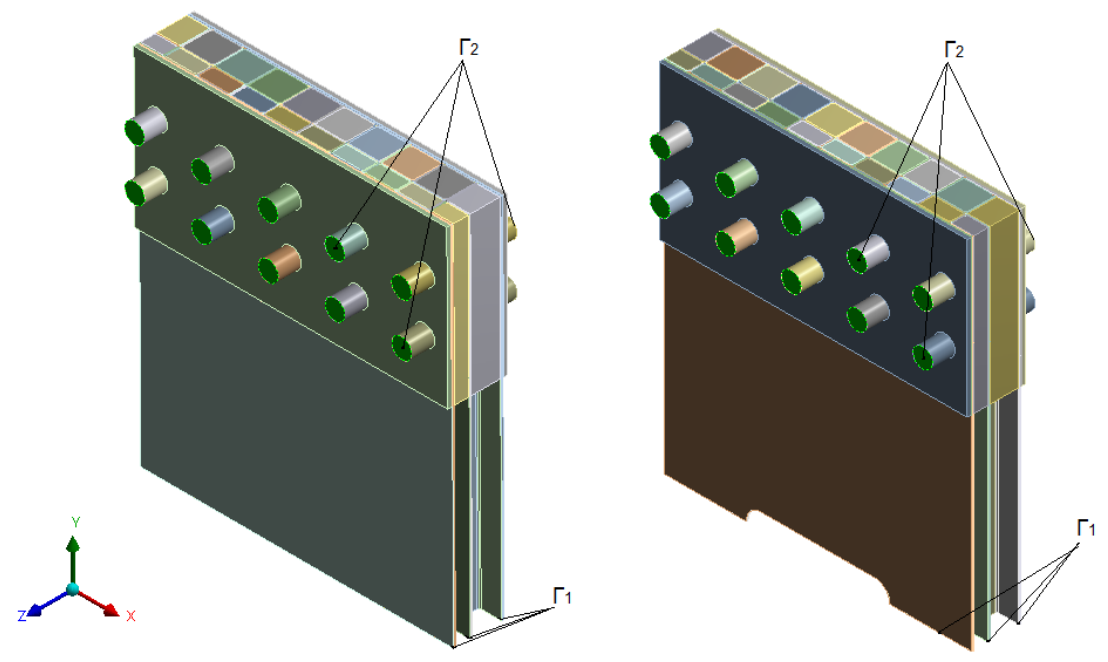

(a)

(b)

Figure 8. Boundary conditions: $\mathrm{a}$ - non-damaged SAP; b - dmaged SAP 
C: Static Structural

Total Deformation

Type: Total Deformation

Unit: $\mathrm{mm}$

Time: 1

21.05.2014 23:51

$\mathbf{1 , 2 2 3}$ Max
1,1688
1,1501
0,94568
0,77815
0,61062
0,4431
0,27557
0,10804
$\mathbf{0 , 0 2 1 6 8 5}$ Min
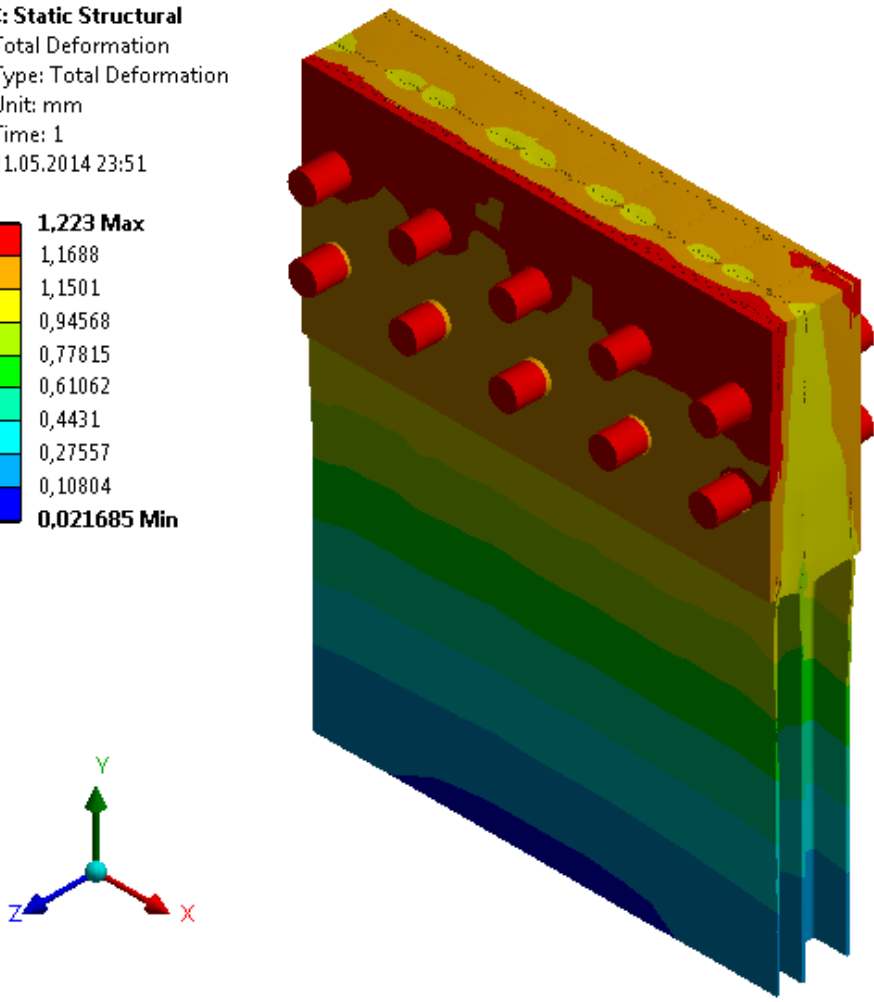

(a)

C: Static Structural Total Deformation Type: Total Deformation Unit: $\mathrm{mm}$

Time: 1

$30.05 .201414: 12$

1,522 Max

1,4439

1,2932

1,1426

0,99187

0,84119

0,6905

0,53982

0,38913

0,35301 Min
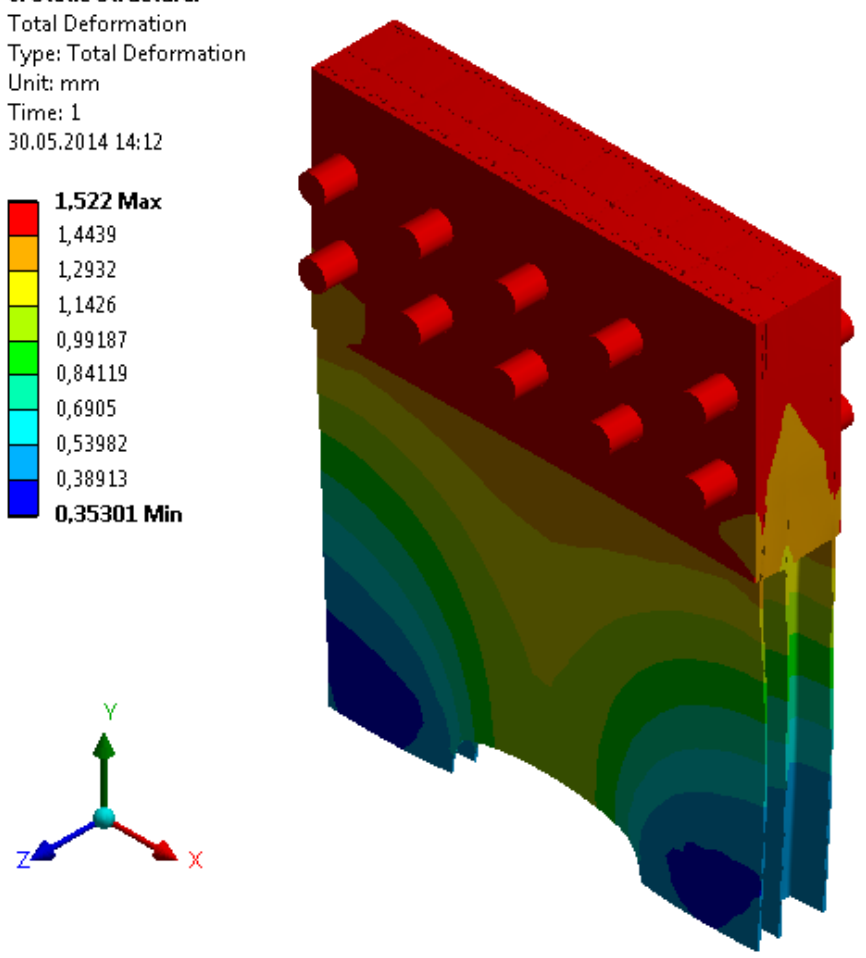

(b) 
Figure 10. Total displacement: a - standard specimen; b - damaged specimen
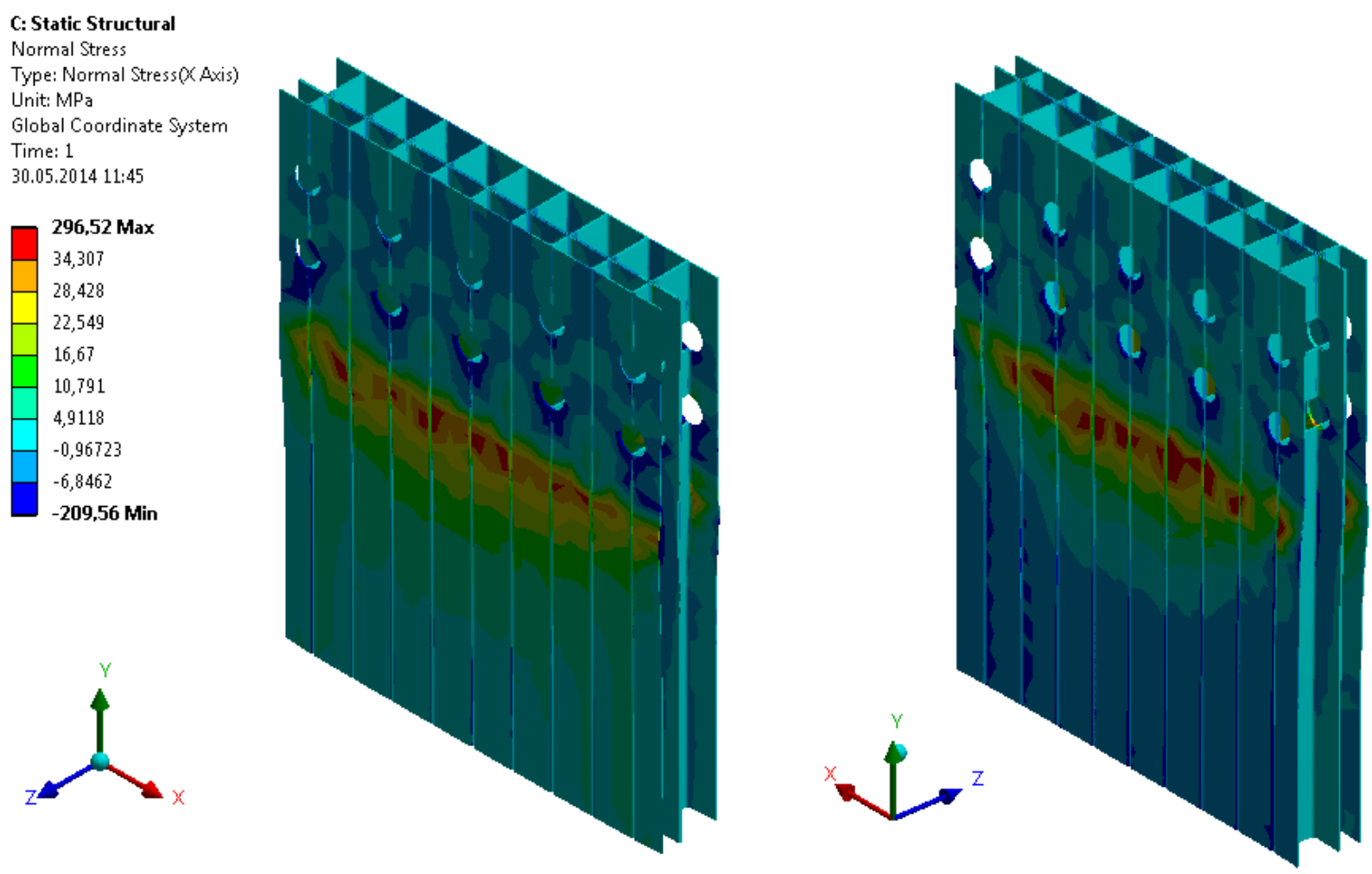

(a)

C: Static Structural

Normal Stress

Type: Normal Stress( $(\mathrm{Axis})$ Unit: $\mathrm{MPa}$

Global Coordinate System Time: 1

30.05.2014 11:27
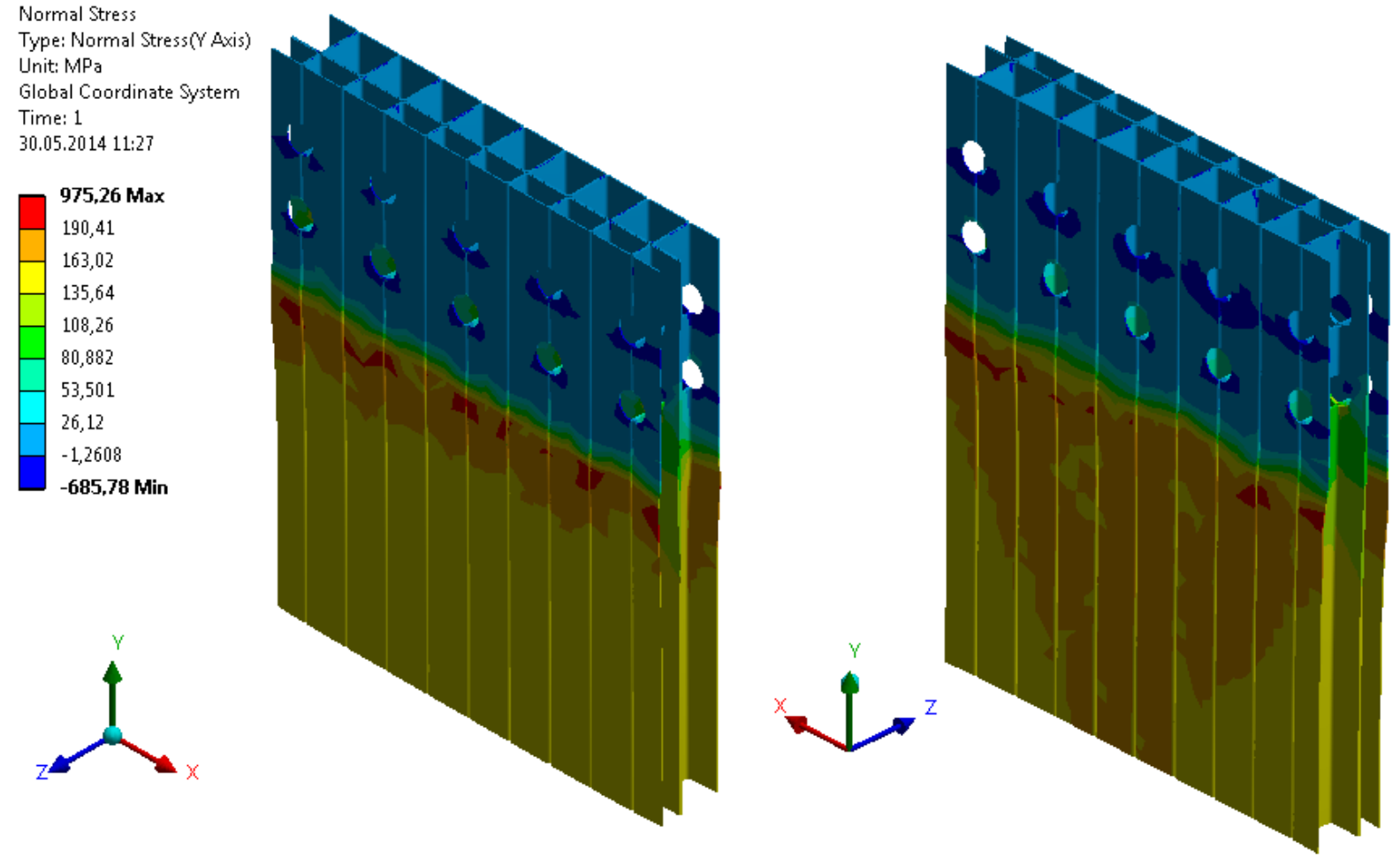

(b) 

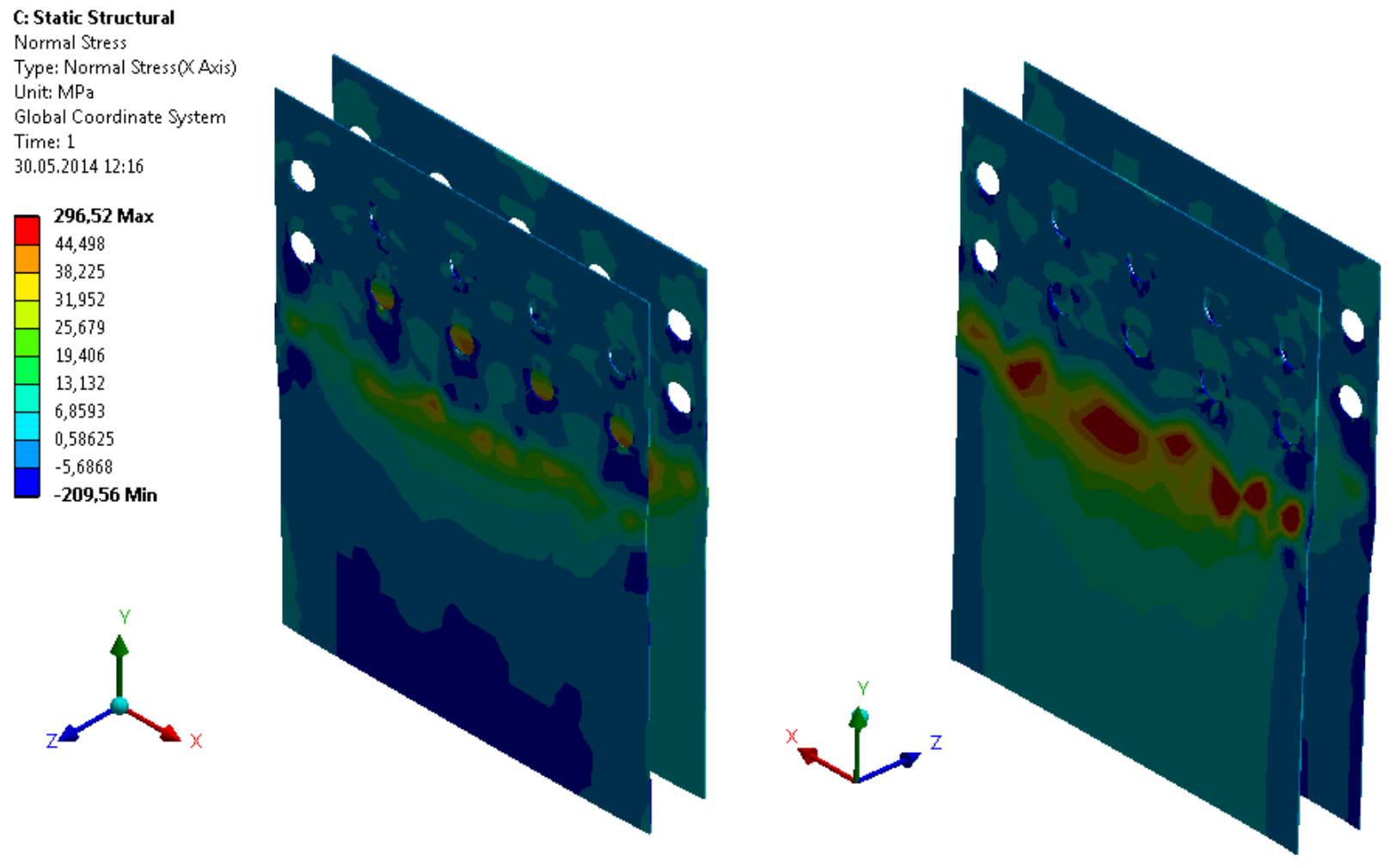

(c)

C: Static Structural Normal Stress

Type: Normal Stress(N Axis) Unit: MPa

Global Coordinate System

Time: 1

$30.05 .201412: 13$

\begin{tabular}{|l|l}
$\mathbf{9 7 5 , 2 6}$ Max \\
253,67 \\
221,77 \\
189,88 \\
157,98 \\
126,09 \\
94,193 \\
62,298 \\
30,403 \\
$-1,4919$ \\
\hline$-685,78$ Min
\end{tabular}
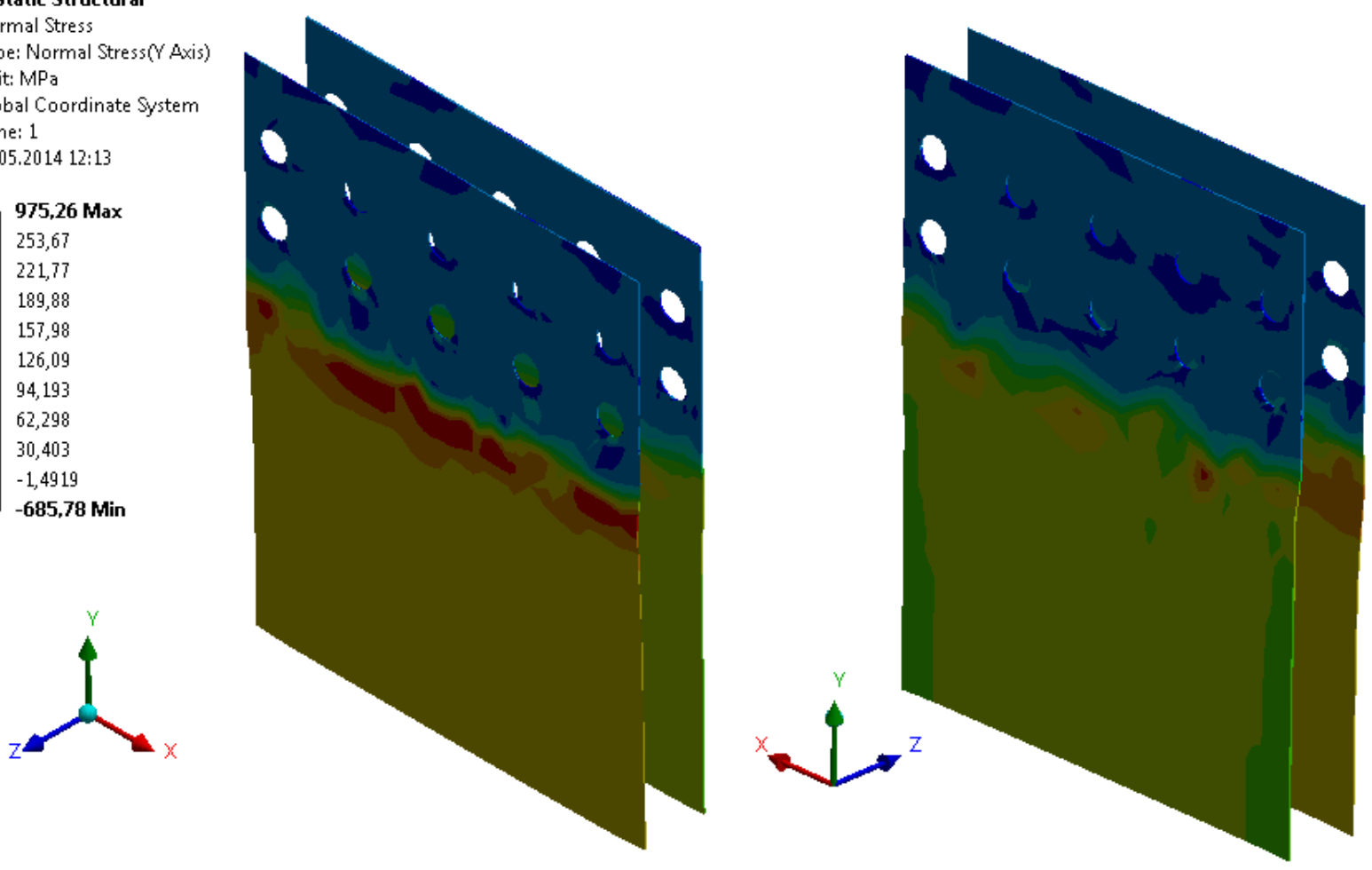

(d)

Figure 10. Distribution of $\sigma_{X}$ and $\sigma_{Y}$ (in MPa) in tubes (a and b, respectively) and 
skins (c and d) of standard sample

C: Static Structural

Normal Stress

Type: Normal Stress $\propto$ Axis)

Unit: $\mathrm{MPa}$

Global Coordinate System

Time: 1

$30.05 .201414: 57$

\begin{tabular}{|l}
$\mathbf{3 1 5 , 1 3}$ Max \\
132,38 \\
110,5 \\
88,625 \\
66,746 \\
44,868 \\
22,989 \\
1,11 \\
$-40,887$ \\
$-82,885$ \\
$-124,88$ \\
$-\mathbf{5 1 7 , 6 8}$ Min
\end{tabular}
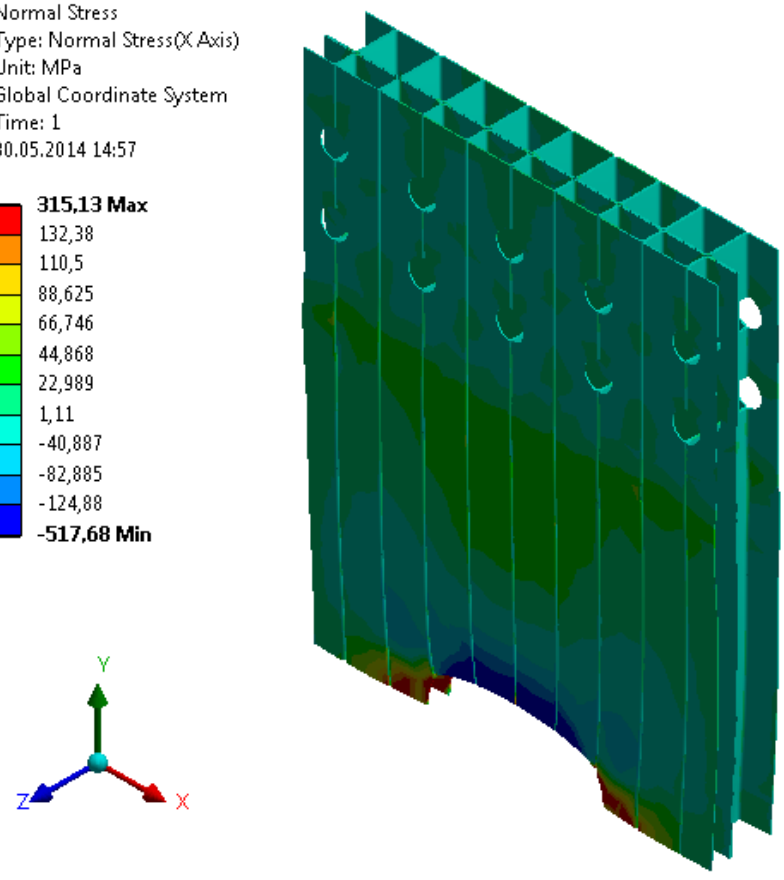

(a)

C: Static Structural

Normal Stress

Type: Normal Stress( $(\mathrm{Axis})$ Unit: MPa

Global Coordinate System Time: 1

30.05.2014 14:56

\begin{tabular}{|l}
$\mathbf{1 5 8 6 , 6}$ Max \\
676,9 \\
564,27 \\
451,64 \\
339,01 \\
226,37 \\
113,74 \\
1,11 \\
1,11 \\
1,11 \\
1,11 \\
$\mathbf{- 4 1 1 , 2 1 ~ M i n}$
\end{tabular}
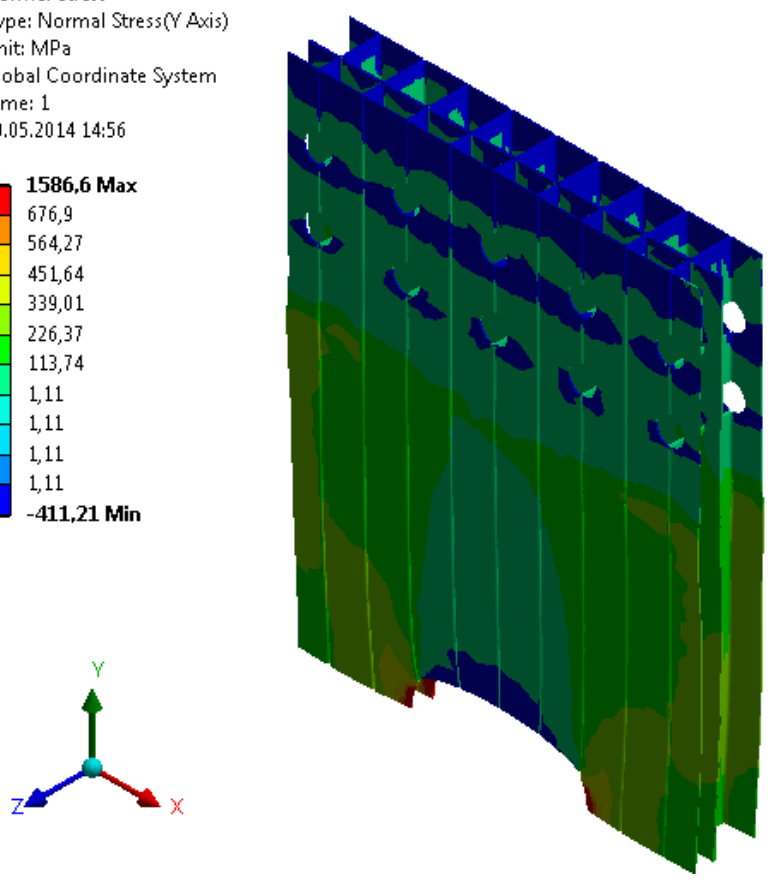

(b) 
C: Static Structural

Normal Stress

Type: Normal Stress $\propto($ Axis $)$

Unit: $\mathrm{MPa}$

Global Coordinate System

Time: 1

30.05.2014 15:00

315,13 Max

132,38

110,5

88,625
66,746

44,868

44,868
22,989

1,11

$-40,887$

$-82,885$

$-124,88$
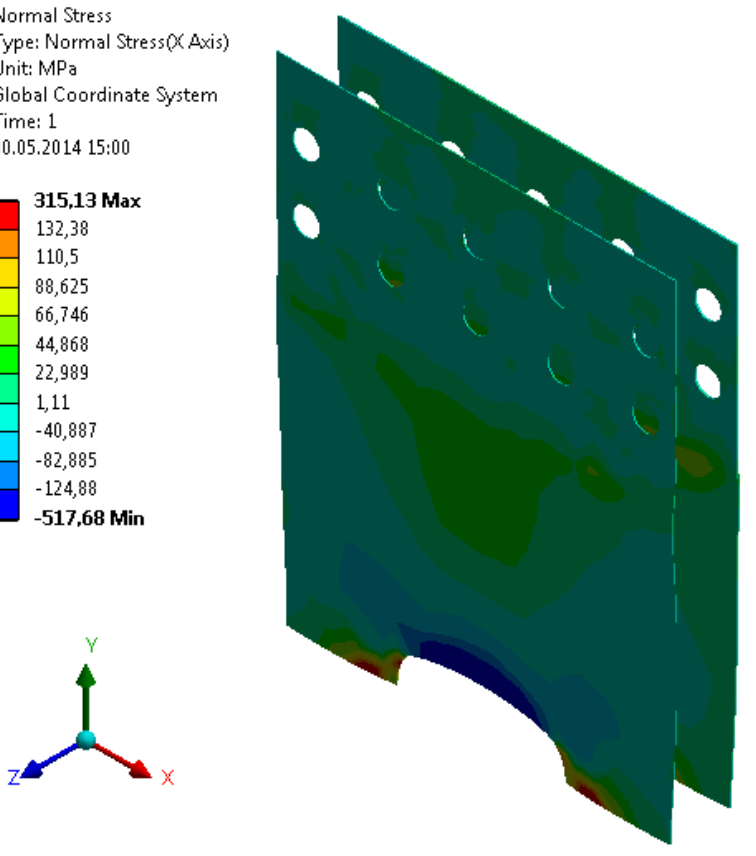

(c)

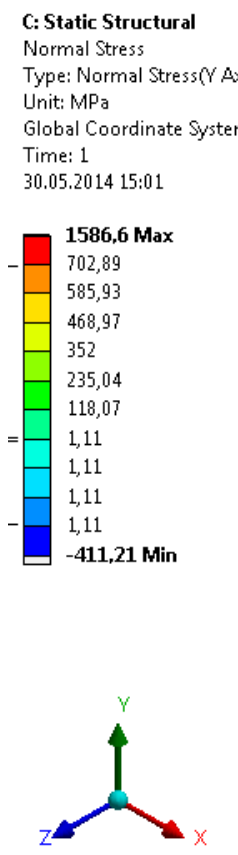

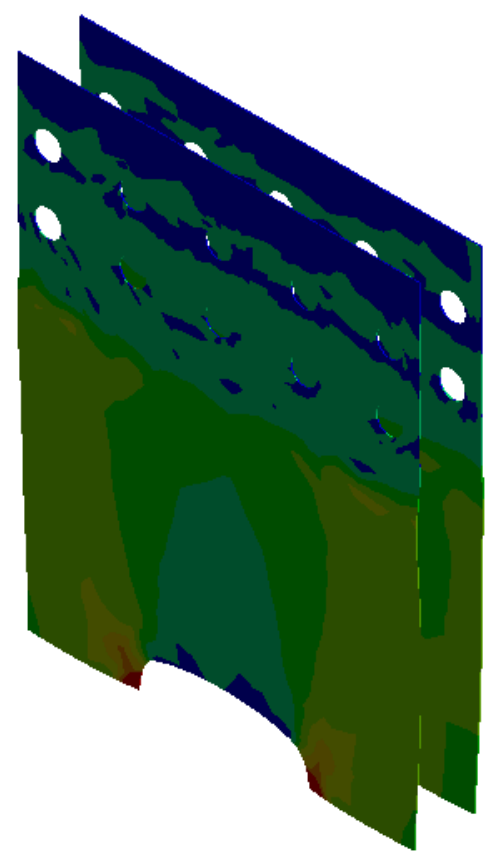

(d)

Figure 11. Distribution of $\sigma_{X}$ and $\sigma_{Y}$ (in MPa) in tubes (a and b, respectively) and skins (c and d) of damaged specimen 


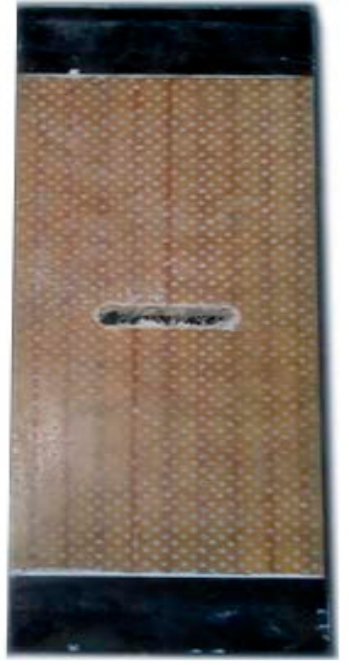

(a)

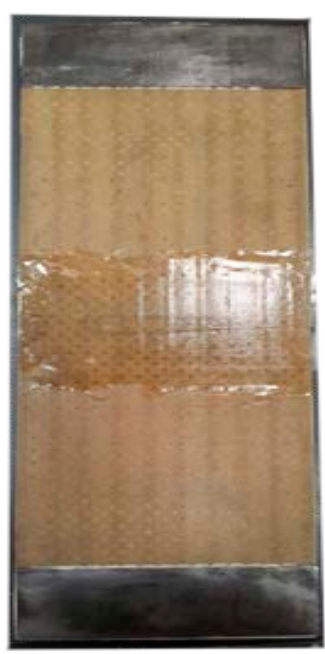

(b)

Figure12. SAPs sample with defect before (a) and after (b) repair
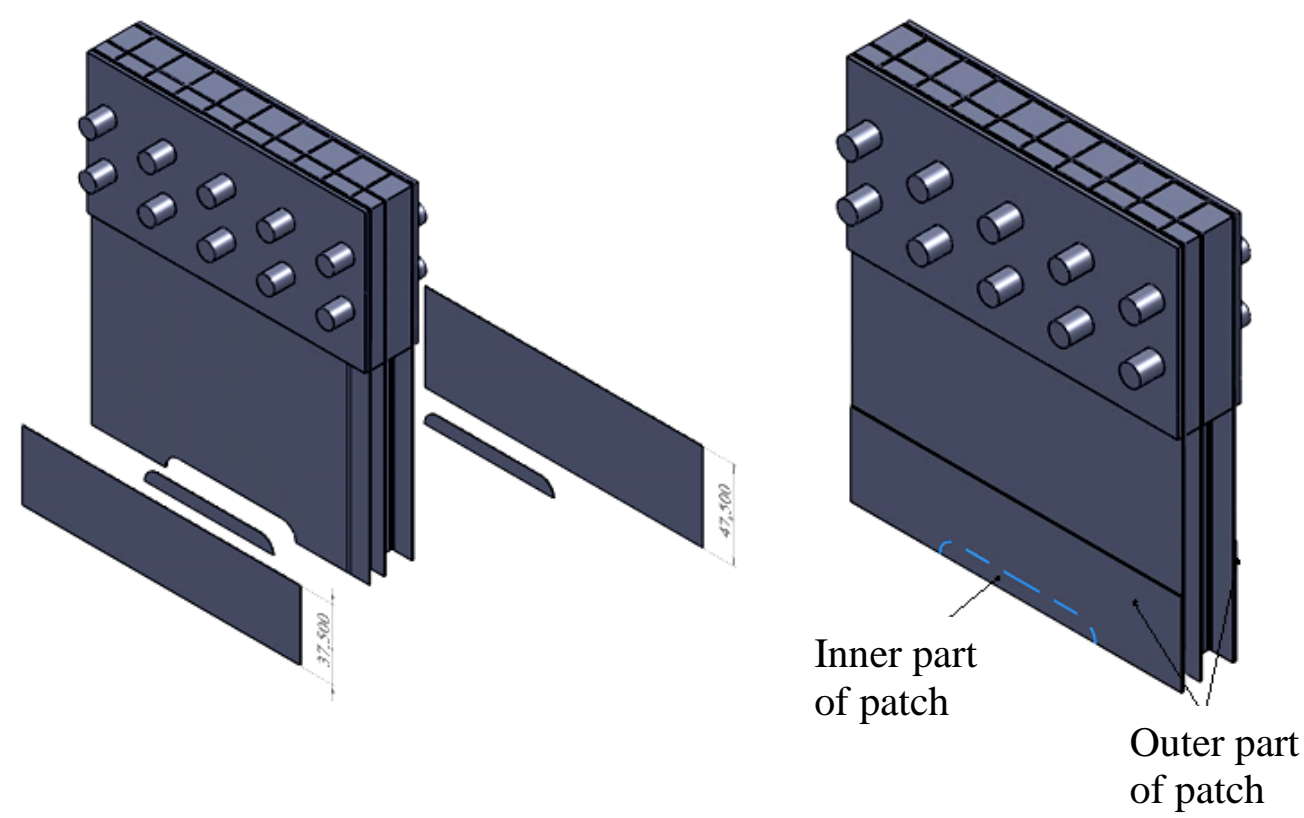

Figure 13. 3D FE model of repaired SAP 


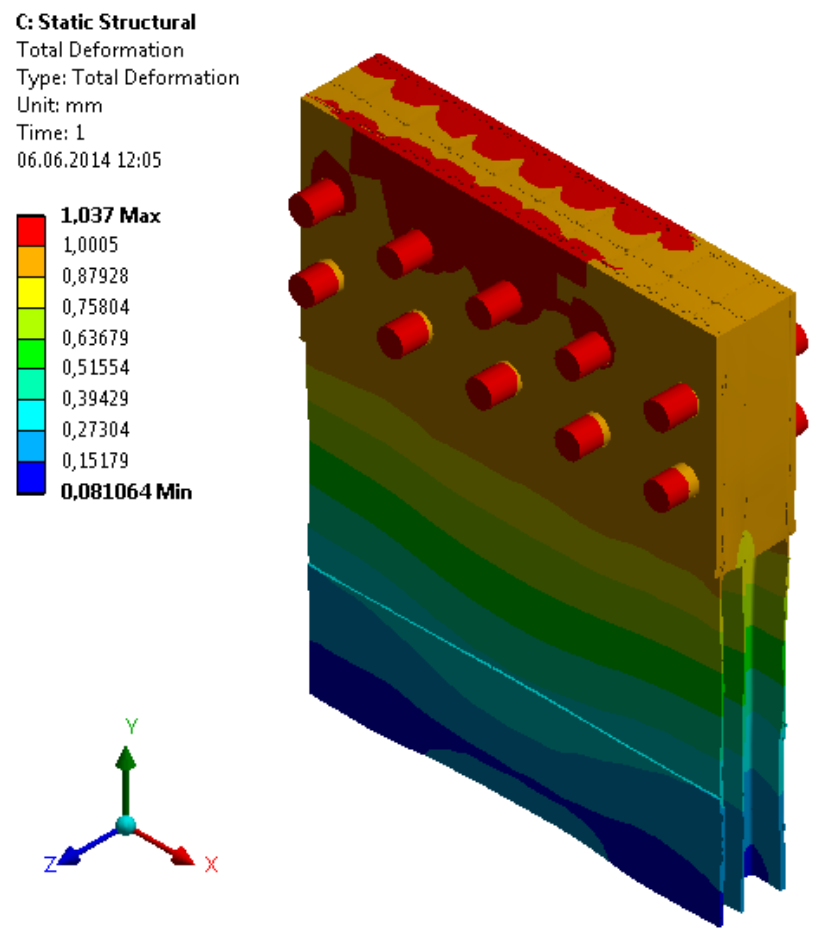

Figure 14. Total displacement of repaired sample

C: Static Structural
Normal Stress
Type: Normal Stress $\propto$ Axis $)$
Unit: MPa
Global Coordinate System
Time: 1
$06.06 .201412: 15$
\begin{tabular}{|l}
219,8 Max \\
29,791 \\
25,01 \\
20,23 \\
15,45 \\
10,67 \\
5,8901 \\
1,11 \\
$-2,4854$ \\
$-6,0808$ \\
$-9,6762$ \\
$-250,57$ Min
\end{tabular}
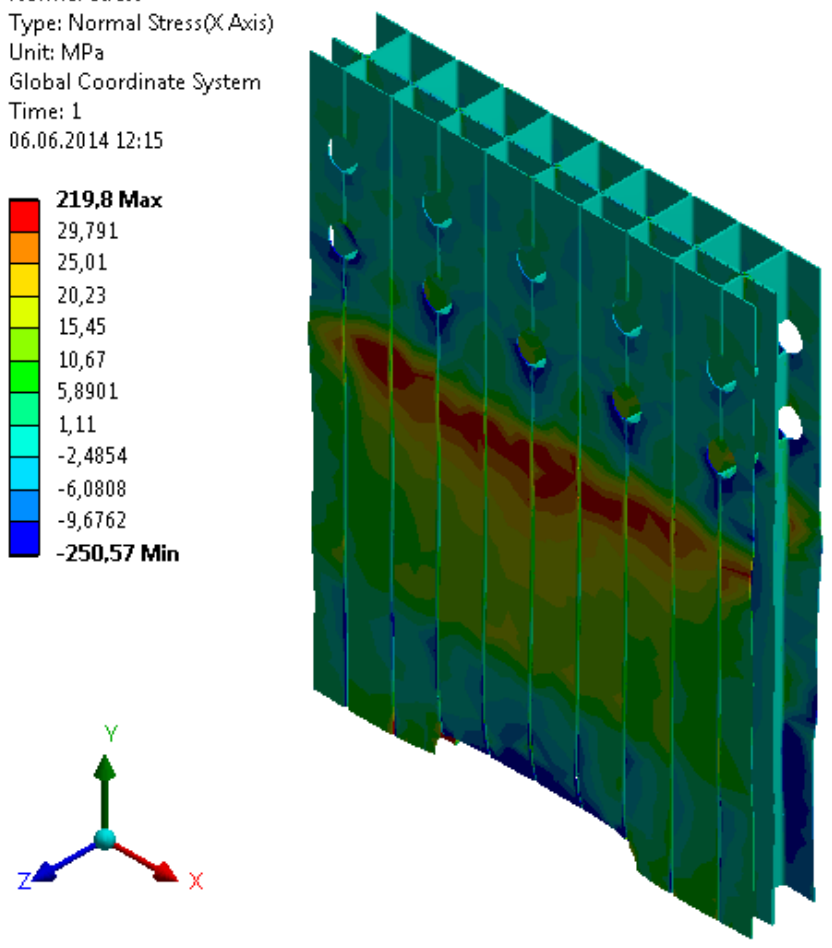

(a) 
C: Static Structural

Normal Stress

Type: Normal Stress( $(\mathrm{Axis}$ )

Unit: $\mathrm{MPa}$

Global Coordinate System

Time: 1

$06.06 .201412: 18$
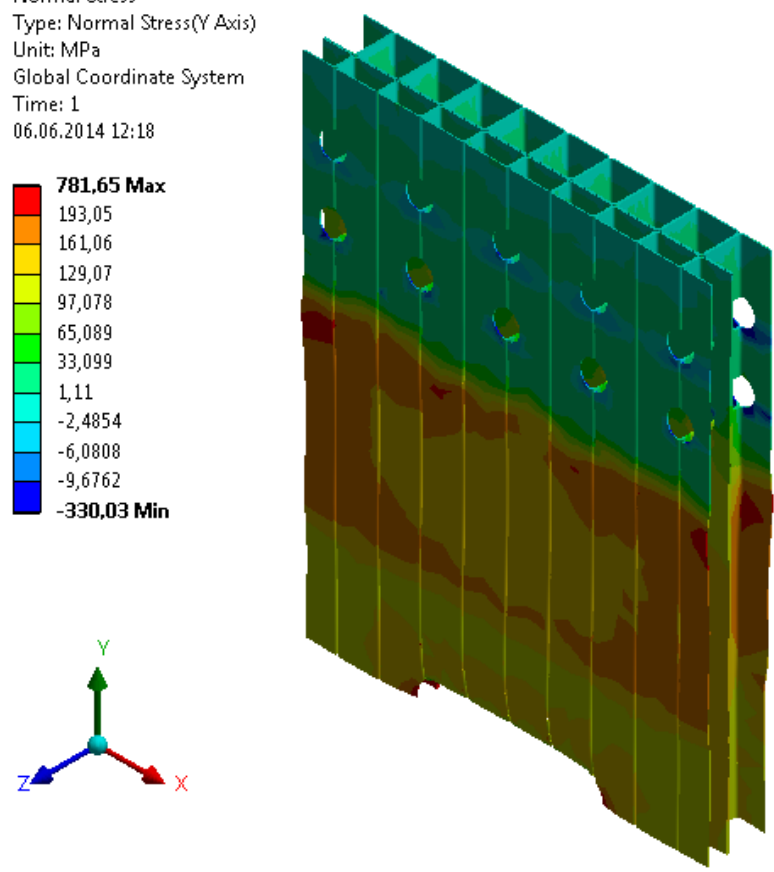

(b)

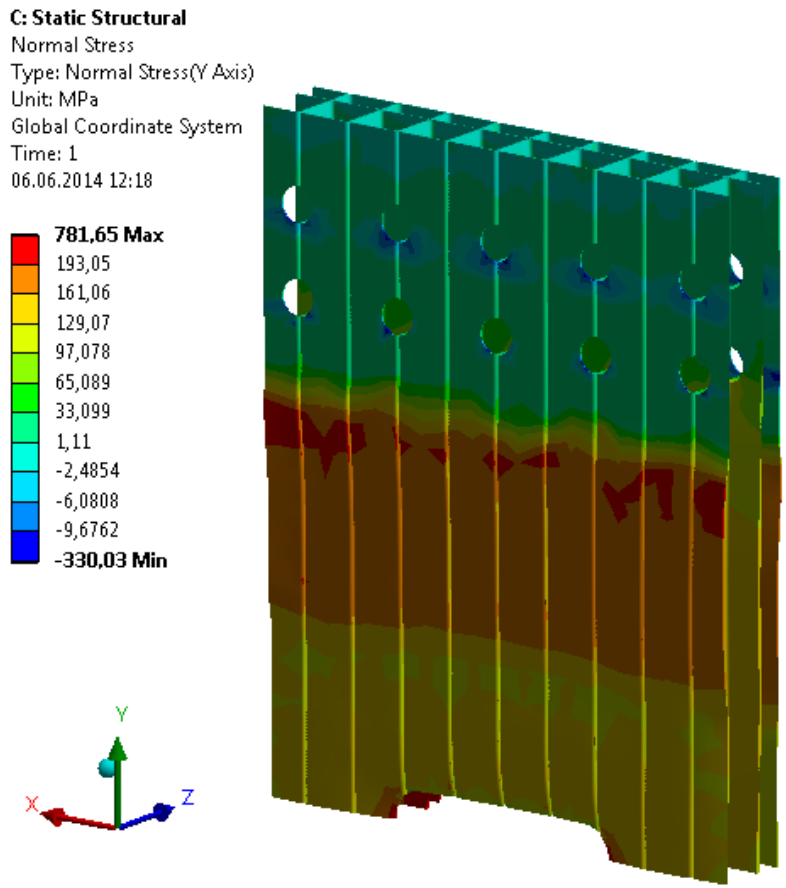

(c)

Figure 15 Distribution of $\sigma_{X}$ (a) and $\sigma_{Y}$ (b, c) (in MPa) in tubes of repaired sample

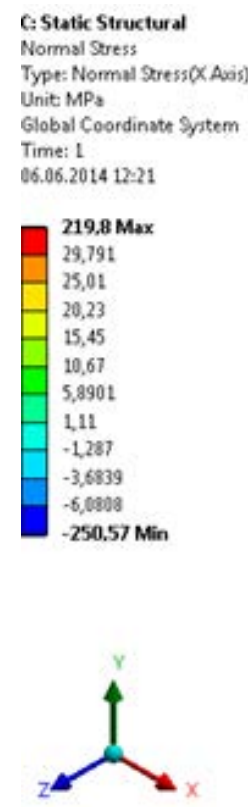

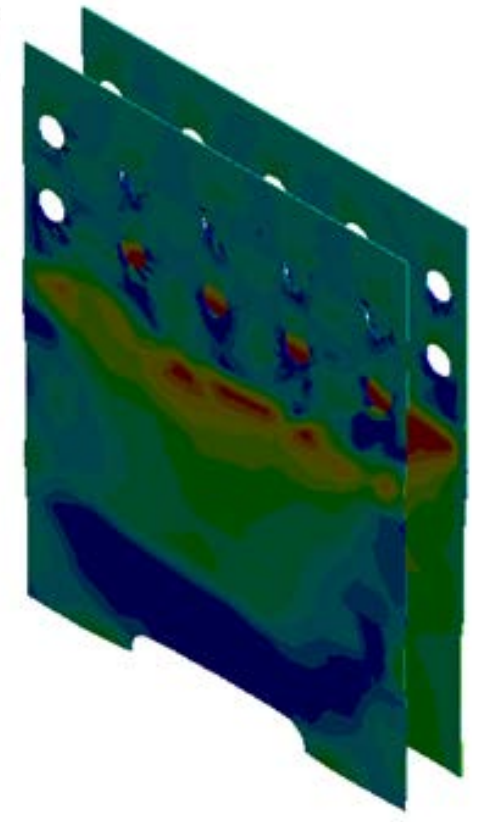

(a)

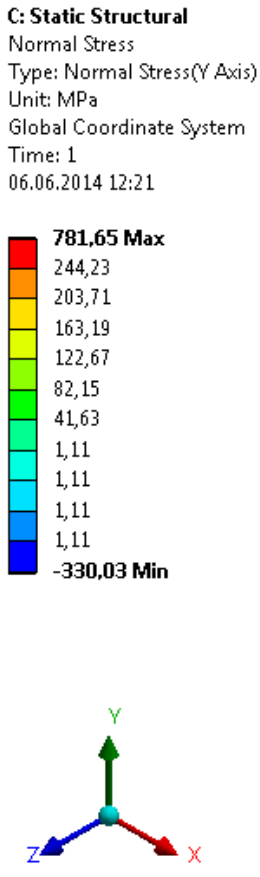

(b)

Figure 16. Distribution of $\mathbf{r X ~ ( a ) ~ a n d ~} \mathbf{r Y}(\mathbf{b})$ (in MPa) in skins of repaired sample 
C: Static Structural

Normal Stress

Type: Normal Stress $\propto$ Axis

Unit: $\mathrm{MPa}$

Global Coordinate System

Time: 1

$06.06 .201412: 40$

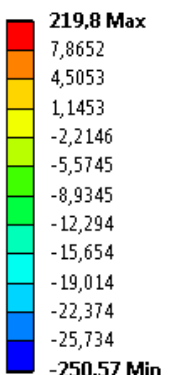

$-250,57 \mathrm{Min}$

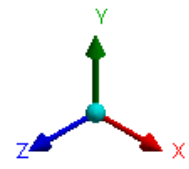

(a)
C: Static Structural

Normal Stress

Unit: $\mathrm{MPa}$

Time: 1

06.06 .201412 .38

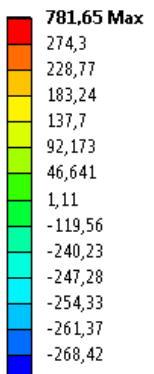

$-330,03$ Min

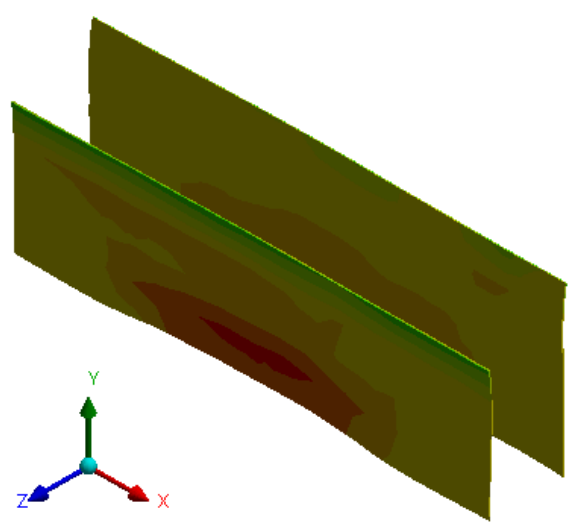

(b)

Figure 17. Stress distributions (in MPa) in patches of repaired sample: (a) $\sigma_{X}$; (b) $\sigma_{Y}$ sample

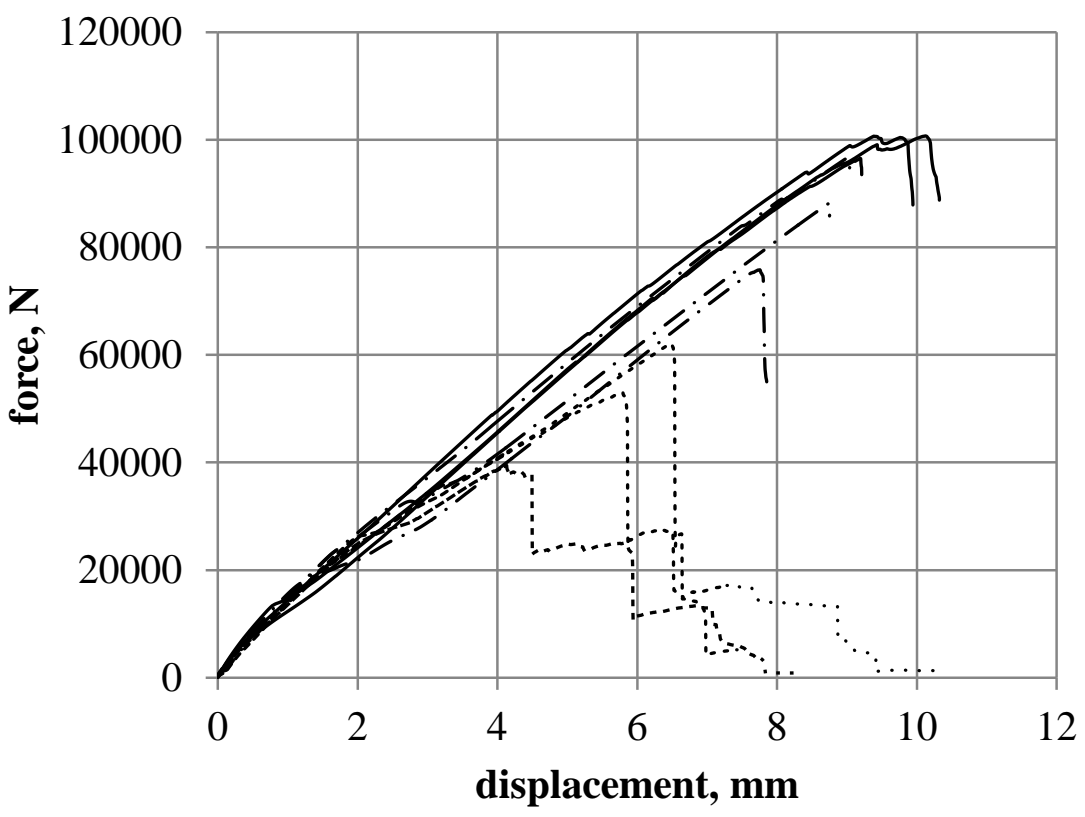

— Standard samples

- - - Repaired samples Samples with defect

(a)

(b)

Figure 18. Experimental loading curves for SAP samples in tension 